IZA DP No. 5476

Incentive Effects of Risk Pooling, Redistributive and Savings Arrangements in Unemployment Benefit Systems:

Evidence from a Job-Search Model for Brazil

David A. Robalino

Eduardo Zylberstajn

Juan David Robalino

February 2011 


\title{
Incentive Effects of Risk Pooling, Redistributive and Savings Arrangements in Unemployment Benefit Systems: Evidence from a Job-Search Model for Brazil
}

\author{
David A. Robalino \\ World Bank and IZA \\ Eduardo Zylberstajn \\ Getúlio Vargas Foundation, Brazil \\ Juan David Robalino \\ Imperial College, London \\ Discussion Paper No. 5476 \\ February 2011 \\ IZA \\ P.O. Box 7240 \\ 53072 Bonn \\ Germany \\ Phone: +49-228-3894-0 \\ Fax: +49-228-3894-180 \\ E-mail: iza@iza.org
}

Any opinions expressed here are those of the author(s) and not those of IZA. Research published in this series may include views on policy, but the institute itself takes no institutional policy positions.

The Institute for the Study of Labor (IZA) in Bonn is a local and virtual international research center and a place of communication between science, politics and business. IZA is an independent nonprofit organization supported by Deutsche Post Foundation. The center is associated with the University of Bonn and offers a stimulating research environment through its international network, workshops and conferences, data service, project support, research visits and doctoral program. IZA engages in (i) original and internationally competitive research in all fields of labor economics, (ii) development of policy concepts, and (iii) dissemination of research results and concepts to the interested public.

IZA Discussion Papers often represent preliminary work and are circulated to encourage discussion. Citation of such a paper should account for its provisional character. A revised version may be available directly from the author. 


\title{
ABSTRACT \\ Incentive Effects of Risk Pooling, Redistributive and Savings Arrangements in Unemployment Benefit Systems: Evidence from a Job-Search Model for Brazil
}

\begin{abstract}
We develop a model of job search and use it to assess the effects that the Brazilian unemployment benefit system has on exit rates from unemployment. In our setup, unemployed workers receive job offers from the formal and informal sectors and decide whether to accept them or wait. Only jobs in the formal sector come with unemployment benefits. After incorporating the rules of the Brazilian unemployment benefit system we estimate the parameters of the model using its labor force survey (a rotating panel). Key parameters determining model dynamics are: the distribution of wage offers for each individual; the observed probabilities of separation from formal and informal jobs; and the unobserved job offers arrival rates. The results show that, in general, workers eligible for unemployment benefits also have higher offer rates - their unobserved characteristic are correlated with more job opportunities. Policy simulations ten suggest that the risk pooling and savings component of the unemployment benefit system have small effects on the probabilities of remaining unemployed. The main effect of both schemes is to reduce transitions into informal jobs. The effects are larger for unskilled workers, particularly women. The simulations also show that current effects are conditioned on the design of the system. More generous unemployment benefits, for instance, could substantially increase the share of workers who remain unemployed. In addition, asking workers to contribute to finance unemployment benefits would reduce formal employment.
\end{abstract}

JEL Classification: J63, J64, J65

Keywords: $\quad$ social protection, unemployment insurance, labor market transitions, job-search models, structural estimations

Corresponding author:

David A. Robalino

World Bank

1818 H Street, NW, MSN G7-703

Washington, DC 20433

USA

E-mail: robalino@worldbank.org 


\section{Introduction}

Most middle and low income countries rely on severance pay as the mechanism to provide income protection to workers. These systems are regulated through the labor code and offer workers a lump-sum upon separation, which is a function of the length of the employment spell. For instance, one month of salaries for each year of employment. There are three important flaws with these systems. First, because employers do not provision for their severance liabilities workers are exposed to the risk of default (see Saavedra, 2005). Second, certifying eligibility for severance pay can be a complex and long process often involving courts (see Holzmann and Vodopivec, 2011). And third, severance pay increases the cost of lay-offs and can reduce turnover (see Kugler, 1999; Gonzaga, 2003; and Saavedra and Torero, 2004) and employment creation (see Pages and Montenegro, 1999; Montenegro and Pages, 2003; Elmeskob et al. (forthcoming)).

Despite these flaws, however, countries have been slow in moving to other forms of unemployment benefits systems, either classic unemployment insurance (risk pooling) or unemployment savings accounts. One of the reasons is the belief that providing unemployment benefits can increase the unemployment rate and lead to unsustainable fiscal costs. The unemployment rate can increase through two channels. First, because reservation wages increase and workers may be less likely to accept job offers at prevailing wages. Second, because workers can have lower incentives to search for and keep jobs. Enforcing job search and controlling abuse is difficult, particularly when there is a large informal sector and institutional capacity is week. Clearly, unemployment benefits also have a potential upside at the micro level. Even if workers spend more time unemployed, they may also be more effective searching for jobs and have more flexibility in choosing among them, which can lead to better matches for their skills. Nonetheless, concerns with "moral hazard" have dominated the policy debate.

Most of the evidence about the incentive effects of unemployment benefits (UB), however, comes from high income countries and even there it is mixed. The first studies on the effect of classic unemployment insurance showed that higher benefits - either a higher replacement rate or a longer duration - did increase the length of the unemployment spell and the unemployment rate (for reviews see Holmlund, 1998; Vodopivec et al, 2005; and Olinto et al., 2007). The estimated benefit elasticity was in the 0.2-0.9 range, whereas the duration elasticity was in the 0.4-0.5 range. These studies also found little evidence of better matches. More recent studies for Denmark, France, Germany, Italy, Ireland and Spain show, on the contrary, that thanks to unemployment benefits workers are able to find more stable jobs, and that even if the length of the unemployment spell increases, the net effect is positive (Tatsiramos, 2009).

Among middle income countries the empirical evidence is quite scant and also inconclusive given the difficulties in separating the effect of the UB system from the effect of unobserved individual characteristics. Two studies for Brazil find no meaningful effect of the UB system on the duration of the unemployment spell. The first exploited changes in eligibility conditions and showed that, if anything, unemployment benefits allowed faster transitions into self-employment (Cuningham, 2000). A second compared the exit 
rates from unemployment among formal sector workers (eligible for unemployment benefits) and informal sector workers (not eligible for unemployment benefits). It showed that the former had higher exit rates even after trying to control for unobserved characteristics that are correlated with work in the formal sector (Margolis, 2008). At the other extreme, van Ours and Vodopivec (2009) show that in the case of Slovenia the shortening of the potential duration of UI benefits reduced substantially the length of the unemployment spell.

We argue that even if one had conclusive evidence about how the presence of a given unemployment benefit system affects workers behaviors, it would be of little help for policymaking. Indeed, at the end, it is likely that the effect of an unemployment benefit system on workers' behaviors depends on particular designs, not only in terms of the level and duration of benefits but more importantly on how it combines risk pooling, savings, and redistributional arrangements. Thus, from a policy perspective, the more relevant question is how individuals would respond to alternative designs of the UB system. Responding to this question requires having a (behavioral) model linking a generic unemployment benefit systems to decisions regarding job search and the acceptance of job offers.

In this paper we analyze, ex-ante, how different changes in the rules of the Brazilian UB would affect exit rates from unemployment. To this end, we develop and estimate a model of job-search that takes detailed account of both the Brazilian unemployment insurance system and the unemployment savings accounts (FGTS). For tractability, the focus is on the effects that alternative components of the system have on the decision to accept job offers. Thus, we do not analyze how unemployment benefits affect the decisions to search for and keep jobs; these are modeled as exogenous factors. These decisions are of course critical and ignoring them hides an important part of the story. Still, a better understanding of how changes in unemployment benefit systems affect reservation wages and through these channel transitions out of unemployment can already help improve the design of current arrangements.

The core of the paper is organized in six sections. Sections 2 and 3 presents the structural model and the data used in the estimation. Section 4 discusses the estimation strategy and its results while section 5 presents the simulation results. Section 6 concludes. The Brazilian unemployment benefit system is described in the annex. Also in the annex we discuss identification issues and show numerically that the likelihood function has indeed a unique solution.

\section{The Model}

We focus on the decision to accept a given job offer. At each time $t$, unemployed individuals can be offered a formal or informal sector job and need to decide whether to take it or wait for another offer. In part because of tractability, we deviate from the standard job-search models (see Diamond, 1982; Mortensen, 1986; and Pissarides, 1990 and new applications such as Vroman et al., 2009) where fully rational workers 
solve a Bellman equation that capture the utility gains/losses of taking a job or waiting for the next offer. ${ }^{1}$ Instead, we assume that individuals are quasi-myopic. They do not solve the full recursive optimization problem but look ahead a given number of periods and project expected revenues taking into account the risk of separation from the job. Depending on whether the job is formal (F) or informal (I) its expected monetary value is given by:

$$
V(j)=w_{j}\left[\sum_{t=0}^{T}\left(\frac{\left(1+g_{j}\right)^{t}}{(1+r)^{t}}\left(1-\mu_{j}\right)^{t}+\frac{\left(1+g_{j}\right)^{t}}{(1+r)^{t}}\left(1-\mu_{j}\right)^{t-1}\left(S_{j}+d_{j} b_{j}\right) \cdot \mu_{j}\right)+c\right],
$$

where $\log \left(w_{j}\right) \sim N\left(W_{j}, \sigma_{j}\right)$ is the realization of the wage in sector $j$ (formal or informal), $g$ is the growth rate of wages, $r$ is a discount rate, $\mu_{j}$ is the probability of separation from the job in sector $j, S_{j}$ are the accumulations of acquired rights in unemployment savings accounts, $d_{j}$ the number of months individuals can receive unemployment benefits, $b_{j}$ is the replacement rate, $c$ is the number of salaries in the form of unemployment benefits that the worker can carry over if working, and $T$ is the planning horizon. ${ }^{2}$

Simplifying, we have:

$$
V(j)=w_{j} A_{j}
$$

where $A_{j}=\left(\frac{\theta_{j}-\theta_{j}^{T+1}}{1-\theta_{j}}\right)\left(1+d_{j} b_{j} \frac{\mu_{j}}{1-\mu_{j}}\right)$ and $\theta_{j}=\left(\frac{(1+g)\left(1-\mu_{j}\right)}{(1+r)}\right)$.

Individuals also calculate the monetary value of the decision to "wait" for another job offer. It is given by:

$$
E[V(0)]=\sum_{t=1}^{T} \sum_{j} \frac{b_{j t} w_{j}}{(1+r)^{t}}\left(1-v_{j}\right)^{t-1}+\sum_{t=1}^{T}\left[\left(v_{F} E[V(F)]+v_{I} E[V(I)]\right) \cdot\left(\frac{\left(1-v_{F}-v_{I}\right)}{(1+r)}\right)^{t}\right]
$$

where $b_{j t}$ is the replacement rate that the individual receives at time $\mathrm{t}$ (for the long-term unemployed $b_{j t}$ is likely to be zero) and $v_{F}$ and $v_{I}$ are the probabilities of being offered a formal or informal sector job at time $\mathrm{t}>1 .^{3}$ The expectations operator $E$ is introduced because at time $t>1$ the realization of the wage for the offered job is not known.

\footnotetext{
${ }^{1}$ One of the reasons for this formulation of the problem is the presence of savings in the Brazilian unemployment benefit system which complicates considerably the standard recursive problem. Workers deciding whether to take a job offer or not would need to simultaneously compute their optimal savings rate. The other reasons are the complexities of the unemployment insurance system which has discontinuities in benefits that depend on the vesting period and income levels.

${ }^{2}$ Formals jobs come with other benefits such as pensions that are not considered here for tractability. We also ignore the social security contribution that workers pay to finance these benefits. The implicit assumption is that the contributions are linked to benefits.

${ }^{3}$ These probabilities depend on the duration of the unemployment spell. To simplify the notation we ignore this point here. It will be taken into account later in the estimation of the model.
} 
Simplifying, we have: ${ }^{4}$

$$
E[V(0)]=\sum_{t=1}^{T} \sum_{j} \frac{b_{j t} w_{j}}{(1+r)^{t}}\left(1-v_{j}\right)^{t-1}+\left[\frac{\left(\frac{\left(1-v_{F}-v_{I}\right)}{(1+r)}\right)^{T}-1}{\frac{\left(1-v_{F}-v_{I}\right)}{(1+r)}-1}\right] \cdot\left(v_{F} E[V(F)]+v_{I} E[V(I)]\right)
$$

Assuming that individuals are risk neutral or risk adverse, a job offer $(j=F$ or $j=I)$ will be taken as long as ${ }^{5}$ :

$$
V(j) \geq E[V(0)]
$$

This simple setup allows to explicitly define the reservation wage $w^{R}$ as:

$$
w_{j}^{R}=\frac{E[V(0)]}{A_{j}}
$$

Notice that the reservation wage is sector dependent. This means that if $A_{j}>A_{\tilde{\jmath}}$, then $w_{j}^{R}<w_{\tilde{J}}^{R}$, which means that employees compensate the lack of future benefits by increasing their reservation wage. Also, from equation (6) and consistently with other findings in the literature, ${ }^{6}$ we see that an increase (decrease) in unemployment benefits or in the expected wages leads to an increase (decrease) in the reservation wage.

This simply setup implies that increasing unemployment benefits increases the value of waiting (individuals are likely to stay unemployed for longer) but also the value of formal job offers relative to informal job offers. Increasing accumulations on the unemployment individual accounts, on the other hand, increases the value of formal sector jobs only and through this channel the value of waiting if workers get informal sector job offers. In other words, savings would not increase the length of the unemployment spell if only formal sector jobs were offered. With informal offers, however, savings do provide incentives to wait. $^{7}$

The model as currently setup can be used to predict transition probabilities out of unemployment that depend on the rules of the unemployment benefit system. To do so, one needs to know (estimate) the distribution of offered wages for different individuals, their growth rate $(g)$, the offer arrival rates $\left(v_{F}, v_{I}\right)$

\footnotetext{
${ }^{4}$ Since in Brazil only formal workers are entitled to UI benefits, equation 4 simplifies to $E[V(0)]=\sum_{t=1}^{T} \frac{b_{F t} w_{j}}{(1+r)^{t}}(1-$ $v F) t-1+(1-v F-v I)(1+r) T-1(1-v F-v I)(1+r)-1 \cdot(v F E V F+v I E V I)$

${ }^{5}$ Notice that we do not take into account preferences on leisure. Since individuals are seeking for jobs, we assume that the decision of participating in the labor force has already been taken.

${ }^{6}$ See, for instance, Wolpin (1987).

${ }^{7}$ Here it is important to observe that this result is particular to the Brazilian system where savings are financed by employers. If savings were financed directly from workers' contributions (meaning higher savings would imply lower wages) and the interest rate paid was equal to workers' discount rate, savings would drop from equation (1).
} 
which will depend on the unemployment duration and the discount rate. This can be done if one has access to a panel with data on wages and other socioeconomic and demographic characteristics for individuals transiting out of unemployment or staying unemployed. Section 4 presents the details of the proposed estimation strategy and the results. Before doing so, we introduce the data used in our application for Brazil.

\section{Data Used to Estimate the Model}

We work with the Pesquisa Mensal de Emprego (PME), or Monthly Employment Survey, which is a monthly rotating panel of dwellers in six metropolitan areas in Brazil (São Paulo, Rio de Janeiro, Belo Horizonte, Salvador, Porto Alegre and Recife), compiled by the Instituto Nacional de Geografia e Estatística (IBGE), or Brazilian National Statistical Agency. These six metropolitan areas cover approximately 25\% of the country's population. The PME survey was redesigned in March, 2002. We used data since then until August, 2010.

The survey investigates schooling, labor force, demographic, and earnings characteristics of each resident aged 10 or more that lives in the interviewed households. This results in approximately 100,000 individuals from 35,000 households every month. The rotating scheme is as follows. Households are interviewed once per month during four consecutive months after which they stay out of the survey for an eight-month window. After this period, the household is interviewed again for another four month period. Once this last spell is finished, the household is permanently excluded from the sample. Households are divided into four rotating groups, in order to make sure that in two consecutive months $75 \%$ of the sample is the same. The PME does not identifies individuals directly, only their households. Thus, to create a sample of individuals a matching process needs to take place. We match individuals within households over time using date of birth (month and year) and gender.

The dataset used for the estimation and the simulations was built based on monthly transitions. We match individuals that were surveyed for two consecutive months and consider this matching as an observation. Characteristics such as gender, age, marital status and schooling are taken from the first interview, together with labor status. The subsequent interview is used only to provide the new labor status. Since we are interested in modeling the decision of leaving unemployment, out of all the observations, we use only those that contain individuals unemployed at time $t$. As discussed in Robalino et al. (2009), we define formal workers as those who have a signed labor card (signed carteira). Self employed, civil servants and employers were excluded from the sample, since we are focusing at this point only on transitions from unemployment to an offered job, either formal or informal. ${ }^{8}$

There is one critical piece of information needed for the model that is not part of the survey: the actual number of monthly unemployment benefits unemployed individuals have the right to cash. To

\footnotetext{
${ }^{8}$ A full model would need to take into account simultaneously choices among three types of jobs: formal wage earner, informal wage earner, and self-employment. In this version of the paper we are assuming implicitly that the workers who remained in the sample did not find self-employment opportunities that were worth it. For them the relevant decision was only whether to take formal or informal sector jobs.
} 
overcome this, a synthetic variable was built based on the length of the observed unemployment spell and that of previous job (if formal). Indeed, only individuals who were fired from a formal job are entitled to receive UI benefits and the number of payments depends on the number of months workers stayed on the former job. Since the PME survey asks to those who are unemployed whether the last job was formal or informal, how long they worked, what was the wage, and why they left, it is trivial to build this synthetic variable. $9^{9}$

All matched individuals, regardless of their labor status, summed a total of 4,817,690 observations. Considering only the unemployed that transit into formal or informal sector jobs or remained unemployed resulted in a dataset with 181,763 observations (3.8\% of the total). Table 1 presents some simple descriptive statistics of the data set. We see that we have a quite diverse sample of individuals both in terms of gender, education, ethnicity, and geographic location. It is worth noting that among the eligible, the percentage of males and educated workers is higher than in the general population. The average age of the eligible is also higher while the length of the unemployment spell is much lower ( 2 vs. 8 months).

Table 1 - Descriptive statistics

\begin{tabular}{|c|c|c|c|c|c|c|c|c|c|}
\hline & \multicolumn{3}{|c|}{ Eligible } & \multicolumn{3}{|c|}{ Non eligible } & \multicolumn{3}{|c|}{ Entire sample } \\
\hline & \# & $\%$ & Std. Dev. & $\#$ & $\%$ & Std. Dev. & $\#$ & $\%$ & Std. Dev. \\
\hline Male & 6,149 & $62 \%$ & - & 73,899 & $43 \%$ & - & 80,048 & $44 \%$ & - \\
\hline Female & 3,776 & $38 \%$ & - & 97,939 & $57 \%$ & - & 101,715 & $56 \%$ & - \\
\hline Married & 4,429 & $45 \%$ & - & 110,296 & $64 \%$ & - & 114,725 & $63 \%$ & - \\
\hline Not married & 5,496 & $55 \%$ & - & 61,542 & $36 \%$ & - & 67,038 & $37 \%$ & - \\
\hline $0-7$ years of education & 2,074 & $21 \%$ & - & 44,692 & $26 \%$ & - & 46,766 & $26 \%$ & - \\
\hline $8-10$ years of education & 2,025 & $20 \%$ & - & 39,075 & $23 \%$ & - & 41,100 & $23 \%$ & - \\
\hline $11+$ years of education & 5,826 & $59 \%$ & - & 88,071 & $51 \%$ & - & 93,897 & $52 \%$ & - \\
\hline White & 4,880 & $49 \%$ & - & 69,649 & $41 \%$ & - & 71,916 & $40 \%$ & - \\
\hline Non-white & 5,045 & $51 \%$ & - & 102,189 & $59 \%$ & - & 103,084 & $57 \%$ & - \\
\hline Region of Recife & 800 & $8 \%$ & - & 18,404 & $11 \%$ & - & 45,550 & $25 \%$ & - \\
\hline Region of Salvador & 1,382 & $14 \%$ & - & 39,028 & $23 \%$ & - & 31,860 & $18 \%$ & - \\
\hline Region of Belo Horizonte & 1,618 & $16 \%$ & - & 22,341 & $13 \%$ & - & 23,028 & $13 \%$ & - \\
\hline Region of Rio de Janeiro & 1,470 & $15 \%$ & - & 31,690 & $18 \%$ & - & 17,010 & $9 \%$ & - \\
\hline Region of São Paulo & 3,089 & $31 \%$ & - & 44,258 & $26 \%$ & - & 38,584 & $21 \%$ & - \\
\hline Region of Porto Alegre & 1,566 & $16 \%$ & - & 16,117 & $9 \%$ & - & 18,709 & $10 \%$ & - \\
\hline Average age & 31.2 & - & 9.6 & 29.5 & - & 10.3 & 29.6 & - & 10.3 \\
\hline $\begin{array}{l}\text { Average unemployment } \\
\text { spell (months) }\end{array}$ & 2.0 & - & 3.1 & 8.1 & - & 11.1 & 7.8 & - & 11.0 \\
\hline Total observations & 9,925 & $100 \%$ & - & 171,838 & $100 \%$ & - & 181,763 & $100 \%$ & - \\
\hline
\end{tabular}

Source: PME (IBGE); Authors' calculations

\footnotetext{
${ }^{9}$ Unemployed individuals who are not receiving unemployment benefit because these run out are considered ineligible - even if they were eligible when they first became unemployed. This is important for the estimation, since these workers face the same optimization problem as those who became unemployed but did not have unemployment benefits. It is likely, however, that eligible workers who run out of benefits have unobserved characteristics that distinguishs them both from the eligible receiving benefits and the "truly" not-eligible. In this version of the paper, however, they are classified as non-eligible.
} 
After following the procedure described above, there were a total of 9,925 unemployed individuals (or 5.5\% of the sample) eligible for unemployment benefits (see bottom line of Table 1). For this subgroup, Table 2 displays statistics about the replacement rates and the (synthetic) number of installments to be cashed. The lowest replacement rate is slightly above $30 \%$ while the maximum is $100 \%$. The average number of remaining benefits is 1.85 , the minimum is obviously 1 (if the person is not receiving unemployment benefits she is considered not eligible) and the maximum is 4 . It is important to note that workers can receive 3, 4 or 5 monthly benefits depending on the amount of time spent in a formal job. Nevertheless, the maximum number we see in Table 2 is 4 because we consider that the eligible unemployed individuals already cashed at least one benefit.

\section{Table 2 - Estimated replacement rate and number of benefits still to be cashed by eligible} unemployed individuals

\begin{tabular}{|c|c|c|}
\hline & $\begin{array}{c}\text { Replacement } \\
\text { Rate } \\
\end{array}$ & $\begin{array}{c}\text { Number of benefits } \\
\text { to be cashed }\end{array}$ \\
\hline Mean & 0.752 & 1.852 \\
\hline Std. dev. & 0.114 & 0.904 \\
\hline Median & 0.800 & 2 \\
\hline Minimum & 0.315 & 1 \\
\hline Maximum & 1.000 & 4 \\
\hline
\end{tabular}

Source: Authors' calculations based on PME (IBGE)

Tables $3 \mathrm{a}$ and $3 \mathrm{~b}$ displays the frequencies of unemployed individuals for different groups transiting to formal and informal jobs. We again see that transitions into formal jobs are more common among workers eligible for unemployment benefits. Transitions into formal jobs are also more common in the South and South East than in the North, and among adult rather than young workers. The effect of education, on the other hand, is less clear. 
Table 3a-Observed transitions from unemployment, non-eligible individuals

\begin{tabular}{|c|c|c|c|c|c|c|c|c|}
\hline \multirow[b]{3}{*}{ Gender } & \multirow[b]{3}{*}{ Schooling } & \multirow[b]{3}{*}{ Age group } & \multirow[b]{3}{*}{ Region } & \multirow{3}{*}{$\begin{array}{c}\text { Number of } \\
\text { observations }\end{array}$} & \multicolumn{4}{|c|}{ Transition to } \\
\hline & & & & & \multicolumn{2}{|c|}{ Formal jobs } & \multicolumn{2}{|c|}{ Informal jobs } \\
\hline & & & & & $\#$ & $\%$ & $\#$ & $\%$ \\
\hline \multirow{12}{*}{ Male } & \multirow{4}{*}{$0-7$ years } & \multirow{2}{*}{$>24$ years } & South/Southeast & 9,945 & 326 & $3.3 \%$ & 770 & $7.7 \%$ \\
\hline & & & Northeast & 5,575 & 65 & $1.2 \%$ & 257 & $4.6 \%$ \\
\hline & & \multirow{2}{*}{$<=24$ years } & South/Southeast & 3,580 & 104 & $2.9 \%$ & 324 & $9.1 \%$ \\
\hline & & & Northeast & 2,672 & 16 & $0.6 \%$ & 146 & $5.5 \%$ \\
\hline & \multirow{4}{*}{$8-10$ years } & \multirow{2}{*}{$>24$ years } & South/Southeast & 5,631 & 200 & $3.6 \%$ & 318 & $5.6 \%$ \\
\hline & & & Northeast & 2,930 & 48 & $1.6 \%$ & 120 & $4.1 \%$ \\
\hline & & \multirow{2}{*}{$<=24$ years } & South/Southeast & 6,921 & 215 & $3.1 \%$ & 472 & $6.8 \%$ \\
\hline & & & Northeast & 3,121 & 25 & $0.8 \%$ & 107 & $3.4 \%$ \\
\hline & \multirow{4}{*}{$11+$ years } & \multirow{2}{*}{$>24$ years } & South/Southeast & 11,377 & 393 & $3.5 \%$ & 401 & $3.5 \%$ \\
\hline & & & Northeast & 5,824 & 116 & $2.0 \%$ & 146 & $2.5 \%$ \\
\hline & & \multirow{2}{*}{$<=24$ years } & South/Southeast & 11,502 & 430 & $3.7 \%$ & 513 & $4.5 \%$ \\
\hline & & & Northeast & 4,821 & 78 & $1.6 \%$ & 144 & $3.0 \%$ \\
\hline \multirow{12}{*}{ Female } & \multirow{4}{*}{$0-7$ years } & \multirow{2}{*}{$>24$ years } & South/Southeast & 12,095 & 177 & $1.5 \%$ & 737 & $6.1 \%$ \\
\hline & & & Northeast & 5,649 & 21 & $0.4 \%$ & 214 & $3.8 \%$ \\
\hline & & \multirow{2}{*}{$<=24$ years } & South/Southeast & 3,193 & 36 & $1.1 \%$ & 174 & $5.4 \%$ \\
\hline & & & Northeast & 1,983 & 3 & $0.2 \%$ & 78 & $3.9 \%$ \\
\hline & \multirow{4}{*}{$8-10$ years } & \multirow{2}{*}{$>24$ years } & South/Southeast & 7,250 & 137 & $1.9 \%$ & 291 & $4.0 \%$ \\
\hline & & & Northeast & 3,413 & 17 & $0.5 \%$ & 78 & $2.3 \%$ \\
\hline & & \multirow{2}{*}{$<=24$ years } & South/Southeast & 6,496 & 115 & $1.8 \%$ & 310 & $4.8 \%$ \\
\hline & & & Northeast & 3,313 & 20 & $0.6 \%$ & 84 & $2.5 \%$ \\
\hline & \multirow{4}{*}{$11+$ years } & \multirow{2}{*}{$>24$ years } & South/Southeast & 18,739 & 440 & $2.3 \%$ & 626 & $3.3 \%$ \\
\hline & & & Northeast & 10,124 & 88 & $0.9 \%$ & 194 & $1.9 \%$ \\
\hline & & \multirow{2}{*}{$<=24$ years } & South/Southeast & 17,677 & 528 & $3.0 \%$ & 820 & $4.6 \%$ \\
\hline & & & Northeast & 8,007 & 75 & $0.9 \%$ & 195 & $2.4 \%$ \\
\hline
\end{tabular}

Source: Authors' calculations based on PME (IBGE) 
Table 3b-Observed transitions from unemployment, eligible individuals

\begin{tabular}{|c|c|c|c|c|c|c|c|c|}
\hline \multirow[b]{3}{*}{ Gender } & \multirow[b]{3}{*}{ Schooling } & \multirow[b]{3}{*}{ Age group } & \multirow[b]{3}{*}{ Region } & \multirow{3}{*}{$\begin{array}{c}\text { Number of } \\
\text { observations }\end{array}$} & \multicolumn{4}{|c|}{ Transition to } \\
\hline & & & & & \multicolumn{2}{|c|}{ Formal jobs } & \multicolumn{2}{|c|}{ Informal jobs } \\
\hline & & & & & $\#$ & $\%$ & $\#$ & $\%$ \\
\hline \multirow{12}{*}{ Male } & \multirow{4}{*}{$0-7$ years } & \multirow{2}{*}{$>24$ years } & South/Southeast & 1,047 & 47 & $4.5 \%$ & 83 & $7.9 \%$ \\
\hline & & & Northeast & 333 & 9 & $2.7 \%$ & 9 & $2.7 \%$ \\
\hline & & \multirow{2}{*}{$<=24$ years } & South/Southeast & 190 & 8 & $4.2 \%$ & 9 & $4.7 \%$ \\
\hline & & & Northeast & 65 & 0 & $0.0 \%$ & 3 & $4.6 \%$ \\
\hline & \multirow{4}{*}{$8-10$ years } & \multirow{2}{*}{$>24$ years } & South/Southeast & 747 & 55 & $7.4 \%$ & 51 & $6.8 \%$ \\
\hline & & & Northeast & 179 & 4 & $2.2 \%$ & 3 & $1.7 \%$ \\
\hline & & \multirow{2}{*}{$<=24$ years } & South/Southeast & 425 & 23 & $5.4 \%$ & 27 & $6.4 \%$ \\
\hline & & & Northeast & 95 & 1 & $1.1 \%$ & 4 & $4.2 \%$ \\
\hline & \multirow{4}{*}{$11+$ years } & \multirow{2}{*}{$>24$ years } & South/Southeast & 1,561 & 102 & $6.5 \%$ & 75 & $4.8 \%$ \\
\hline & & & Northeast & 527 & 16 & $3.0 \%$ & 21 & $4.0 \%$ \\
\hline & & \multirow{2}{*}{$<=24$ years } & South/Southeast & 789 & 31 & $3.9 \%$ & 37 & $4.7 \%$ \\
\hline & & & Northeast & 191 & 2 & $1.0 \%$ & 8 & $4.2 \%$ \\
\hline \multirow{12}{*}{ Female } & \multirow{4}{*}{$0-7$ years } & \multirow{2}{*}{$>24$ years } & South/Southeast & 318 & 9 & $2.8 \%$ & 31 & $9.7 \%$ \\
\hline & & & Northeast & 53 & 2 & $3.8 \%$ & 2 & $3.8 \%$ \\
\hline & & \multirow{2}{*}{$<=24$ years } & South/Southeast & 61 & 2 & $3.3 \%$ & 5 & $8.2 \%$ \\
\hline & & & Northeast & 7 & 0 & $0.0 \%$ & 0 & $0.0 \%$ \\
\hline & \multirow{4}{*}{$8-10$ years } & \multirow{2}{*}{$>24$ years } & South/Southeast & 320 & 7 & $2.2 \%$ & 22 & $6.9 \%$ \\
\hline & & & Northeast & 76 & 4 & $5.3 \%$ & 2 & $2.6 \%$ \\
\hline & & \multirow{2}{*}{$<=24$ years } & South/Southeast & 158 & 10 & $6.3 \%$ & 6 & $3.8 \%$ \\
\hline & & & Northeast & 25 & 0 & $0.0 \%$ & 1 & $4.0 \%$ \\
\hline & \multirow{4}{*}{$11+$ years } & \multirow{2}{*}{$>24$ years } & South/Southeast & 1,347 & 44 & $3.3 \%$ & 55 & $4.1 \%$ \\
\hline & & & Northeast & 424 & 9 & $2.1 \%$ & 5 & $1.2 \%$ \\
\hline & & \multirow{2}{*}{$<=24$ years } & South/Southeast & 780 & 53 & $6.8 \%$ & 35 & $4.5 \%$ \\
\hline & & & Northeast & 207 & 4 & $1.9 \%$ & 3 & $1.4 \%$ \\
\hline
\end{tabular}

Source: Authors' calculations based on PME (IBGE)

\section{Estimation Strategy}

The estimation proceeds in two steps. Step 1 focuses on the parameters that we consider exogenous to the behavioral model, namely the distribution of wage offers and the probabilities of separation from formal and informal jobs (respectively, $W_{j}, \sigma_{j}$ and $\mu_{j}$ ). Step 2 involves estimating the parameters of the behavioral model, which determine the transition probabilities out of unemployment into formal and informal jobs $\left(v_{j}\right)$.

We begin with the description of the methods used in Step 1. To estimate the wage equation we used a Heckman two-step procedure. The estimation was done separately for formal and informal wages. To control for selection, for each group, we estimated jointly the probability of moving out of unemployment into a formal or informal job and the wage equation. The later uses standard demographic, social and 
education variables. Both models were estimated using dummies for regions and months. The results are presented in Table 4.

Table 4 - Wage and Employment: Heckman Selection Model

\begin{tabular}{|c|c|c|c|c|c|}
\hline & \multirow[b]{2}{*}{ Parameter } & \multicolumn{2}{|r|}{ Informal } & \multicolumn{2}{|c|}{ Formal } \\
\hline & & Coeff. & Std. Err. & Coeff. & Std. Err. \\
\hline \multirow{17}{*}{ 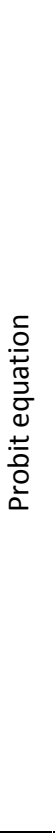 } & Age & $-0.009 *$ & $(0.004)$ & 0.003 & $(0.005)$ \\
\hline & Age squared & 0.000 & $(0.000)$ & $-0.000 *$ & $(0.000)$ \\
\hline & Lenght of unemp. Spell & $-0.018 * * *$ & $(0.001)$ & $-0.020 * * *$ & $(0.002)$ \\
\hline & Lenght of unemp. spell squared & $0.000 * * *$ & $(0.000)$ & $0.000 * * *$ & $(0.000)$ \\
\hline & Female & $-0.108 * * *$ & $(0.011)$ & $-0.219 * * *$ & $(0.015)$ \\
\hline & Chief of the household & $0.087^{* * *}$ & $(0.015)$ & $0.112 * * *$ & (0.019) \\
\hline & Has worked before & $0.160 * * *$ & $(0.018)$ & $0.167^{* * *}$ & $(0.024)$ \\
\hline & Married & $-0.032^{*}$ & $(0.015)$ & $0.077^{* * *}$ & (0.019) \\
\hline & Children under 6 & $0.043^{* *}$ & $(0.016)$ & 0.029 & $(0.021)$ \\
\hline & $0-3$ years of education ${ }^{[1]}$ & $0.316^{* * *}$ & $(0.023)$ & $-0.213^{* * *}$ & $(0.036)$ \\
\hline & $4-7$ years of education ${ }^{[1]}$ & $0.266^{* * *}$ & $(0.015)$ & $-0.176^{* * *}$ & $(0.020)$ \\
\hline & $8-10$ years of education ${ }^{[1]}$ & $0.126^{* * *}$ & $(0.014)$ & $-0.121^{* * *}$ & $(0.018)$ \\
\hline & Log(weekly working hours) & $-1.857 * * *$ & $(0.036)$ & $0.521 * * *$ & $(0.069)$ \\
\hline & Log(desired weekly working hours) & $1.724 * * *$ & $(0.048)$ & -0.106 & $(0.077)$ \\
\hline & Metropolitan area and month dummies & Yes & & Yes & \\
\hline & Regional unemployment rate & $-0.027 * * *$ & $(0.005)$ & $-0.056 * * *$ & $(0.008)$ \\
\hline & Trend & -0.000 & $(0.000)$ & $0.003^{* * *}$ & $(0.000)$ \\
\hline \multirow{17}{*}{ 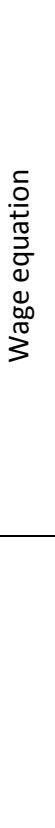 } & Log(weekly working hours) & $0.489 * * *$ & $(0.040)$ & -0.016 & $(0.036)$ \\
\hline & Age & $0.033^{* * *}$ & $(0.004)$ & $0.032 * * *$ & $(0.004)$ \\
\hline & Age squared & $-0.000 * * *$ & $(0.000)$ & $-0.000 * * *$ & $(0.000)$ \\
\hline & Female & $-0.126 * * *$ & $(0.013)$ & $-0.146 * * *$ & $(0.013)$ \\
\hline & White or asian & $0.109 * * *$ & $(0.014)$ & $0.089 * * *$ & $(0.012)$ \\
\hline & $0-3$ years of education ${ }^{[1]}$ & $-0.412^{* * *}$ & $(0.027)$ & $-0.308 * * *$ & $(0.031)$ \\
\hline & 4-7 years of education ${ }^{[1]}$ & $-0.302 * * *$ & $(0.018)$ & $-0.254 * * *$ & $(0.017)$ \\
\hline & $8-10$ years of education ${ }^{[1]}$ & $-0.222 * * *$ & $(0.017)$ & $-0.146 * * *$ & $(0.015)$ \\
\hline & Metropolitan area dummies & Yes & & Yes & \\
\hline & Trend & $0.004 * * *$ & $(0.000)$ & $0.001 * * *$ & $(0.000)$ \\
\hline & Intercept & $3.345^{* * *}$ & $(0.109)$ & $6.009 * * *$ & $(0.183)$ \\
\hline & Rho & 0.291 & 0.052 & -0.271 & 0.074 \\
\hline & Sigma & 0.567 & 0.008 & 0.363 & 0.008 \\
\hline & Lambda & 0.165 & 0.032 & -0.099 & 0.029 \\
\hline & Number of observations & \multicolumn{2}{|r|}{181,763} & \multicolumn{2}{|c|}{181,763} \\
\hline & Number of censored observations & \multicolumn{2}{|r|}{8,016} & \multicolumn{2}{|c|}{4,115} \\
\hline & LR test of indep. equations. $($ Rho $=0)$ : Prob. $>\chi^{2}$ & \multicolumn{2}{|r|}{0.000} & \multicolumn{2}{|c|}{0.002} \\
\hline
\end{tabular}

$* \mathrm{p}<0.05,{ }^{* *} \mathrm{p}<0.01, * * * \mathrm{p}<0.001$. [1] Reference is 11 or more years of education

Source: authors' calculation based on PME (IBGE)

It is important to clarify that the estimation was done using the same database described in the previous section. This means that selection (employment at time $\mathrm{t}$ ) was estimated using all individuals that were unemployed at $\mathrm{t}-1$, whereas wage equations were estimated based on the first salaries received by those 
who exited unemployment. ${ }^{10}$ We see that all parameters have the expected sign and most are significant. Particularly, women and the less educated have lower wages, even after controlling for participation. In addition, the number of children under the age of 6 and being the chief of the household increase the probability of participation in formal jobs. One interpretation is that married workers with families have stronger incentives to find formal sector jobs that, for instance, offer social security benefits. At the same time, being in geographic areas with a high unemployment rate and where finding jobs takes longer provides incentives to take informal sector jobs.

Table 5 - Unemployment Risk Logit Equations

\begin{tabular}{|c|c|c|c|c|c|c|}
\hline & \multicolumn{3}{|c|}{ Informal employee } & \multicolumn{3}{|c|}{ Formal employee } \\
\hline & $\begin{array}{l}\text { Marginal } \\
\text { Effect }\end{array}$ & Coeff. & Std. Err. & $\begin{array}{c}\text { Marginal } \\
\text { Effect }\end{array}$ & Coeff. & Std. Err. \\
\hline Age & $-0.00045^{* * *}$ & $-0.021 * * *$ & $(0.001)$ & $-0.00013^{* * *}$ & $-0.019 * * *$ & $(0.001)$ \\
\hline Lenght of employment spell & $-0.00049 * * *$ & $-0.023 * * *$ & $(0.000)$ & $-0.00012 * * *$ & $-0.019 * * *$ & $(0.000)$ \\
\hline Lenght of employment spell squared & $0.00000 * * *$ & $0.000 * * *$ & $(0.000)$ & $0.00000 * * *$ & $0.000 * * *$ & $(0.000)$ \\
\hline Female & $-0.00237 * * *$ & $-0.110 * * *$ & (0.019) & 0.00008 & 0.012 & $(0.023)$ \\
\hline White $^{[1]}$ & -0.00420 & -0.198 & $(0.196)$ & -0.00272 & -0.410 & (0.239) \\
\hline Asian $^{[1]}$ & -0.00802 & -0.465 & $(0.238)$ & -0.00262 & -0.510 & $(0.286)$ \\
\hline Black $^{[1]}$ & 0.00196 & 0.089 & $(0.197)$ & -0.00139 & -0.233 & $(0.240)$ \\
\hline 'Pardo' ${ }^{[1]}$ & -0.00092 & -0.043 & $(0.196)$ & -0.00224 & -0.357 & (0.239) \\
\hline Married & $-0.00163 * *$ & $-0.077^{* *}$ & $(0.024)$ & $-0.00185^{* * *}$ & $-0.279 * * *$ & $(0.026)$ \\
\hline Married*Female & $-0.00345 * * *$ & $-0.168 * * *$ & $(0.031)$ & -0.00045 & -0.071 & $(0.038)$ \\
\hline Number of dwellers in household & $0.00085^{* * *}$ & $0.040 * * *$ & $(0.004)$ & $0.00021 * * *$ & $0.033 * * *$ & $(0.005)$ \\
\hline $0-3$ years of education ${ }^{[2]}$ & $0.00486 * * *$ & $0.210 * * *$ & $(0.029)$ & $0.00140 * * *$ & $0.197^{* * *}$ & $(0.044)$ \\
\hline $4-7$ years of education ${ }^{[2]}$ & $0.00366 * * *$ & $0.166^{* * *}$ & $(0.020)$ & $0.00103 * * *$ & $0.151^{* * *}$ & $(0.026)$ \\
\hline $8-10$ years of education ${ }^{[2]}$ & $0.00461 * * *$ & $0.204 * * *$ & $(0.020)$ & $0.00172 * * *$ & $0.244 * * *$ & $(0.023)$ \\
\hline Unemployment rate & $0.00149 * * *$ & $0.070 * * *$ & $(0.007)$ & $0.00017 * *$ & $0.027^{* *}$ & (0.009) \\
\hline Log(weekly working hours) & $-0.00759 * * *$ & $-0.355^{* * *}$ & $(0.016)$ & $0.00088 * *$ & $0.134 * *$ & $(0.048)$ \\
\hline Trend & $0.00002 *$ & $0.001 *$ & $(0.000)$ & 0.00000 & 0.001 & $(0.001)$ \\
\hline Constant & & $-1.133^{* * *}$ & $(0.219)$ & & $-3.609 * * *$ & $(0.316)$ \\
\hline $\mathrm{N}$ & & 549,707 & & & $1,363,994$ & \\
\hline Pseudo-R2 & & 0.0799 & & & 0.0524 & \\
\hline
\end{tabular}

[1] Reference is indian

[2] Reference is 11 or more years of education

Note: region and month dummies were included in the estimations

Source: Authors' calculations based on PME (IBGE)

The probabilities of separation from formal and informal jobs were estimated using a simple logit model. The dataset used for this purpose included all the matched individuals that were working at time $t$.

\footnotetext{
${ }^{10}$ Clearly, we do not observe the true distribution of offered wages (only the accepted wages) and it is not possible to correct for this with our current data. This can lead to overestimate the level of offered wages and therefore underestimate job offer rates. This is, however, unlikely to affect our analysis of the effects, at the margin, of the unemployment benefit systems on transition rates towards formal and informal jobs.
} 
Hence, the dichotomous left hand side variable takes the value of 1 if the person becomes unemployed at time $t+1$ or 0 otherwise. The results of the logits are presented in Table 5 and are consistent with our priors. In particular, those who have a lower risk of becoming unemployed are men, older, educated and married workers. Also, the longer individuals have been employed and the more hours they work the lower the probability of separation.

Step 2 is somewhat more complex. For every individual transiting from state 0 (unemployed) to state $s(j=$ employed or $0=$ unemployed $)$ we define the probabilities:

$$
\begin{aligned}
P_{i}(0 & \rightarrow j)=v_{i j}\left(1-v_{\widetilde{\imath}}\right) P_{i}(j>0)+v_{i j} v_{\widetilde{\imath \jmath}} P_{i}(j>\tilde{\jmath}) P(j>0) \\
& =v_{i j} P_{i}(j>0)+v_{i j} v_{\widetilde{\imath}}\left(P(j>0)\left(P_{i}(j>\tilde{\jmath})-1\right)\right)
\end{aligned}
$$

and

$$
P_{i}(0 \rightarrow 0)=1-P_{i}(0 \rightarrow j)-P_{i}(0 \rightarrow \tilde{\jmath})
$$

where $P_{i}(j>0)$ gives the probability that the job taken provides better utility than waiting and is given by:

$$
\begin{gathered}
P_{i}(j>0)=\operatorname{Pr}\left(\log \left(V_{i}(j)\right)>\lambda+\log \left(E\left[V_{i}(0)\right]\right)\right) \\
\quad=\operatorname{Pr}\left(\log \left(w_{i j}\right)>\log \left(E\left[V_{i}(0)\right]\right)-\log A_{i j}\right)
\end{gathered}
$$

Similarly, $P_{i}(j>\tilde{J})$ gives the probability that the job taken provides better utility than a job offer that could have been received from the other sector $(\tilde{J})$ and is given by:

$$
\begin{gathered}
P_{i}(j>\tilde{\jmath})=\operatorname{Pr}\left(\log \left(V_{i}(j)\right)>\log \left(V_{i}(\tilde{\jmath})\right)\right) \\
=\operatorname{Pr}\left(\log \left(w_{i j}\right)-\log \left(w_{i \tilde{\jmath}}\right)>\left(\log A_{i \tilde{\jmath}}-\log A_{i j}\right)\right)
\end{gathered}
$$

Regarding the offer probabilities, the assumption made is slightly different than usual. Normally, more than one offer is allowed to arrive at each period of time following, for instance, a Poisson process. For simplicity, here we assume that only one "credible" formal and one informal offer can be received each month. This offer depends on the length of the unemployment spell and on a time trend, allowing for nonstationarity (see Van den Berg, 1990). Thus we assume that the offer probabilities are given by:

$$
v_{i j}=\frac{1}{1+\exp \left(\beta_{j}+\theta_{j} \cdot \operatorname{spell}+\tau_{j} \cdot t\right)}
$$

where spell is the number of months that individual $i$ is unemployed and $t$ is a trend variable (March/2002 $=1$ and July $/ 2010=101)$.

The goal therefore is to estimate a vector of six parameters $\left[\theta_{F}, \beta_{F}, \tau_{F}, \theta_{I}, \beta_{I}, \tau_{I}\right]$. We do this by maximizing the log likelihood function:

$$
L\left(\theta_{F}, \beta_{F}, \tau_{F}, \theta_{I}, \beta_{I}, \tau_{I}\right)=\sum_{i} \log \left[P_{i}(0 \rightarrow s)\right]
$$


To calculate this likelihood function we need simulated values for $A_{i j}$ and $E\left[V_{i}(0)\right]$. The calculation of $A_{i j}$ is straightforward (recall equation 1). ${ }^{11}$ The parameter $\mu_{j}$ is estimated in the first step, $r$ was assumed to be $6 \%$ per year, $g_{j}$ comes from the wage equation (the trend variable), and $S_{j}$ and $d_{j}$ are calculated based on Brazilian social protection rules. The only missing variable is $b_{j}$ which is calculated by dividing the benefit that the worker would be given if fired (again based on the system's rules) and the expected wage given by the wage equation estimated in the first step. Given $A_{i j}, E\left[V_{i}(0)\right]$ can also be easily calculated. Contrary to $A_{i j}$, however, $E\left[V_{i}(0)\right]$ needs to be estimated at each iteration of the likelihood maximization routine, since its value depends on the value of the job offers arrival rates.

To take into account unobserved heterogeneity that affects the offer rates, the estimation was done for 48 different groups of individuals based on gender, education (low, medium and high ${ }^{12}$ ), age (up to 24 years old or more), region (Northeast or South/Southeast) and current eligibility for unemployment benefits (eligible and non-eligible). However, in the case of eligible workers, some of the subsets had very few observations, which caused the optimization to either not converge or to produce statistically insignificant estimates. Thus, for them the parameters were estimated at a higher level of aggregation excluding age and region.

Tables 6a, 6b, 7a and 7b show the results for the six parameters estimated for the 30 resulting groups (24 non-eligible and 6 eligible). In order to facilitate the interpretation of the parameters $\theta_{j}, \beta_{j}$ and $\tau_{j}$, the tables also show the resulting average offer probabilities. The numbers in parenthesis indicate the standard errors calculated using a re-sampling bootstrap approach.

The results show that job arrival rates are systematically higher among those eligible for unemployment benefits relative to the non-eligible. Offer probabilities are also systematically higher for men than for women, regardless of education, age, region or eligibility conditions. These results are interesting because they suggest that the failure of previous studies for Brazil to find a meaningful effect of the unemployment benefit system on formal and informal employment can be explained by the inability to account for unobserved heterogeneity. Our results suggests that, other things being equal, those eligible for unemployment benefits are also more likely to get job offers presumably because their unobserved cognitive and non-cognitive skills are in higher demand and/or because they have better information and broader social networks. Unemployment benefits could also give them more possibilities. For instance, they could hire counselors or buy better clothing. Nonetheless, all these scenarios are not inconsistent with the

\footnotetext{
${ }^{11}$ Given the complexities of the Brazilian unemployment benefit system - mainly discontinuities that depend on the vesting periods and minimums and maximums -- there are no closed form solutions for the true $A_{i j}$. These are simulated for each individual, but only once. Indeed, the values of the $A_{i j}$ do not change between the iterations of the optimization routine for the likelihood function.

${ }^{12}$ Low educated individuals are those with up to 7 years of schooling; medium indicates a minimum of 8 and a maximum of 11 , while highly educated are those with 12 or more years.
} 
possibility that because of the unemployment benefits, eligible individuals might also invest less time searching for jobs (moral hazard) - an issue that we cannot address with our data.

Table 6a-Parameters estimates for non-eligible men

\begin{tabular}{|c|c|c|c|c|c|c|c|c|c|c|c|}
\hline Education & Age group & Region & & $\theta_{\mathrm{F}}$ & $\beta_{\mathrm{F}}$ & $\tau_{F}$ & $\theta_{\mathrm{I}}$ & $\beta_{\text {I }}$ & $\tau_{I}$ & $\mathbf{v F}$ & $v I$ \\
\hline \multirow{3}{*}{ Low } & \multirow{3}{*}{ Young } & \multirow{3}{*}{ Northeast } & Mean & 0.025 & 5.824 & -0.011 & 0.018 & 1.992 & -0.003 & $0.44 \%$ & $12.11 \%$ \\
\hline & & & Std dev & 0.033 & 0.628 & 0.011 & 0.013 & 0.205 & 0.004 & $0.16 \%$ & $1.14 \%$ \\
\hline & & & t-ratio & 0.77 & 9.27 & -0.94 & 1.35 & 9.73 & -0.76 & 2.70 & 10.61 \\
\hline \multirow{3}{*}{ Medium } & \multirow{3}{*}{ Young } & \multirow{3}{*}{ Northeast } & Mean & 0.048 & 6.002 & -0.022 & 0.039 & 2.667 & -0.010 & $0.63 \%$ & $8.14 \%$ \\
\hline & & & Std dev & 0.050 & 0.682 & 0.010 & 0.020 & 0.314 & 0.005 & $0.15 \%$ & $0.79 \%$ \\
\hline & & & t-ratio & 0.95 & 8.79 & -2.26 & 2.01 & 8.50 & -2.12 & 4.34 & 10.30 \\
\hline \multirow{3}{*}{ High } & \multirow{3}{*}{ Young } & \multirow{3}{*}{ Northeast } & Mean & 0.018 & 5.071 & -0.015 & 0.033 & 2.138 & -0.001 & $1.31 \%$ & $9.08 \%$ \\
\hline & & & Std dev & 0.016 & 0.405 & 0.007 & 0.015 & 0.267 & 0.005 & $0.22 \%$ & $0.84 \%$ \\
\hline & & & t-ratio & 1.08 & 12.52 & -2.23 & 2.17 & 8.01 & -0.17 & 5.93 & 10.85 \\
\hline \multirow{3}{*}{ Low } & \multirow{3}{*}{ Old } & \multirow{3}{*}{ Northeast } & Mean & 0.048 & 5.066 & -0.016 & 0.020 & 2.310 & -0.009 & $0.96 \%$ & $11.13 \%$ \\
\hline & & & Std dev & 0.014 & 0.344 & 0.006 & 0.007 & 0.145 & 0.003 & $0.18 \%$ & $0.82 \%$ \\
\hline & & & t-ratio & 3.56 & 14.75 & -2.66 & 2.89 & 15.91 & -3.36 & 5.21 & 13.64 \\
\hline \multirow{3}{*}{ Medium } & \multirow{3}{*}{ Old } & \multirow{3}{*}{ Northeast } & Mean & 0.041 & 5.038 & -0.021 & 0.060 & 1.712 & -0.002 & $1.49 \%$ & $11.55 \%$ \\
\hline & & & Std dev & 0.014 & 0.424 & 0.006 & 0.015 & 0.224 & 0.004 & $0.24 \%$ & $0.98 \%$ \\
\hline & & & t-ratio & 2.92 & 11.88 & -3.34 & 4.00 & 7.64 & -0.50 & 6.27 & 11.73 \\
\hline \multirow{3}{*}{ High } & \multirow{3}{*}{ Old } & \multirow{3}{*}{ Northeast } & Mean & 0.023 & 4.975 & -0.021 & 0.027 & 2.464 & -0.004 & $1.93 \%$ & $7.89 \%$ \\
\hline & & & Std dev & 0.013 & 0.430 & 0.007 & 0.010 & 0.242 & 0.004 & $0.24 \%$ & $0.66 \%$ \\
\hline & & & t-ratio & 1.69 & 11.57 & -3.10 & 2.73 & 10.18 & -0.97 & 8.09 & 12.04 \\
\hline \multirow{3}{*}{ Low } & \multirow{3}{*}{ Young } & \multirow{3}{*}{ South/Southeast } & Mean & 0.051 & 4.068 & -0.012 & 0.079 & 0.728 & -0.001 & $2.29 \%$ & $25.56 \%$ \\
\hline & & & Std dev & 0.018 & 0.246 & 0.004 & 0.015 & 0.141 & 0.003 & $0.23 \%$ & $1.22 \%$ \\
\hline & & & t-ratio & 2.78 & 16.53 & -2.87 & 5.16 & 5.16 & -0.41 & 10.03 & 20.94 \\
\hline \multirow{3}{*}{ Medium } & \multirow{3}{*}{ Young } & \multirow{3}{*}{ South/Southeast } & Mean & 0.063 & 3.902 & -0.011 & 0.076 & 1.177 & -0.006 & $2.52 \%$ & $22.21 \%$ \\
\hline & & & Std dev & 0.018 & 0.214 & 0.003 & 0.014 & 0.137 & 0.002 & $0.19 \%$ & $0.91 \%$ \\
\hline & & & t-ratio & 3.55 & 18.20 & -3.27 & 5.56 & 8.58 & -2.72 & 13.60 & 24.41 \\
\hline \multirow{3}{*}{ High } & & & Mean & 0.060 & 3.741 & -0.010 & 0.071 & 1.430 & -0.004 & $3.00 \%$ & $17.12 \%$ \\
\hline & Young & South/Southeast & Std dev & 0.021 & 0.278 & 0.005 & 0.014 & 0.209 & 0.004 & $0.20 \%$ & $0.92 \%$ \\
\hline & & & t-ratio & 2.89 & 13.46 & -2.13 & 4.94 & 6.84 & -1.06 & 14.69 & 18.52 \\
\hline & & & Mean & 0.042 & 3.995 & -0.014 & 0.053 & 1.026 & -0.004 & $2.69 \%$ & $23.09 \%$ \\
\hline Low & Old & South/Southeast & Std dev & 0.013 & 0.217 & 0.003 & 0.008 & 0.103 & 0.002 & $0.21 \%$ & $0.78 \%$ \\
\hline & & & t-ratio & 3.25 & 18.41 & -4.32 & 7.05 & 9.95 & -1.98 & 12.80 & 29.77 \\
\hline & & & Mean & 0.069 & 3.742 & -0.013 & 0.073 & 1.363 & -0.006 & $3.13 \%$ & $18.49 \%$ \\
\hline Medium & Old & South/Southeast & Std dev & 0.013 & 0.198 & 0.003 & 0.012 & 0.152 & 0.003 & $0.24 \%$ & $0.91 \%$ \\
\hline & & & t-ratio & 5.49 & 18.87 & -4.18 & 6.17 & 8.99 & -2.44 & 12.95 & 20.42 \\
\hline & & & Mean & 0.066 & 3.865 & -0.017 & 0.083 & 1.789 & -0.005 & $3.79 \%$ & $12.15 \%$ \\
\hline High & Old & South/Southeast & Std dev & 0.015 & 0.217 & 0.003 & 0.011 & 0.158 & 0.002 & $0.29 \%$ & $0.71 \%$ \\
\hline & & & t-ratio & 4.42 & 17.84 & -5.62 & 7.30 & 11.33 & -2.01 & 12.91 & 17.05 \\
\hline
\end{tabular}

Note: Means and standard deviations were calculated using bootstrap resampling techniques

Source: Authors' calculation using PME (IBGE) 
Table $6 \mathrm{~b}$ - Parameters estimates for non-eligible women

\begin{tabular}{|c|c|c|c|c|c|c|c|c|c|c|c|}
\hline Education & Age group & Region & & $\theta_{F}$ & $\beta_{F}$ & $\boldsymbol{\tau}_{\mathbf{F}}$ & $\boldsymbol{\theta}_{\mathrm{I}}$ & $\beta_{I}$ & $\tau_{I}$ & $\mathbf{v F}$ & vI \\
\hline \multirow{3}{*}{ Low } & \multirow{3}{*}{ Young } & \multirow{3}{*}{ Northeast } & Mean & 0.587 & 30.662 & -0.215 & 0.035 & 2.537 & -0.006 & $0.14 \%$ & $7.44 \%$ \\
\hline & & & Std dev & 2.951 & 276.715 & 2.684 & 0.021 & 0.342 & 0.006 & $0.08 \%$ & $0.89 \%$ \\
\hline & & & t-ratio & 0.20 & 0.11 & -0.08 & 1.65 & 7.41 & -0.91 & 1.66 & 8.41 \\
\hline \multirow{3}{*}{ Medium } & \multirow{3}{*}{ Young } & \multirow{3}{*}{ Northeast } & Mean & 0.036 & 4.890 & 0.007 & 0.041 & 2.956 & -0.009 & $0.50 \%$ & $5.80 \%$ \\
\hline & & & Std dev & 0.059 & 0.540 & 0.010 & 0.019 & 0.305 & 0.005 & $0.12 \%$ & $0.72 \%$ \\
\hline & & & t-ratio & 0.61 & 9.05 & 0.73 & 2.11 & 9.69 & -1.85 & 4.10 & 8.07 \\
\hline \multirow{3}{*}{ High } & \multirow{3}{*}{ Young } & \multirow{3}{*}{ Northeast } & Mean & 0.042 & 5.467 & -0.015 & 0.069 & 2.646 & -0.006 & $0.77 \%$ & $6.07 \%$ \\
\hline & & & Std dev & 0.023 & 0.417 & 0.006 & 0.016 & 0.282 & 0.004 & $0.27 \%$ & $1.35 \%$ \\
\hline & & & t-ratio & 1.81 & 13.11 & -2.52 & 4.43 & 9.38 & -1.49 & 2.84 & 4.48 \\
\hline \multirow{3}{*}{ Low } & \multirow{3}{*}{ Old } & \multirow{3}{*}{ Northeast } & Mean & 0.028 & 6.397 & -0.010 & 0.049 & 2.476 & -0.008 & $0.24 \%$ & $7.72 \%$ \\
\hline & & & Std dev & 0.024 & 0.762 & 0.014 & 0.010 & 0.169 & 0.003 & $0.07 \%$ & $0.56 \%$ \\
\hline & & & t-ratio & 1.16 & 8.39 & -0.76 & 4.75 & 14.61 & -2.67 & 3.70 & 13.82 \\
\hline \multirow{3}{*}{ Medium } & \multirow{3}{*}{ Old } & \multirow{3}{*}{ Northeast } & Mean & 0.065 & 5.669 & -0.008 & 0.061 & 2.528 & 0.000 & $0.38 \%$ & $4.94 \%$ \\
\hline & & & Std dev & 0.043 & 0.645 & 0.012 & 0.022 & 0.313 & 0.006 & $0.18 \%$ & $0.69 \%$ \\
\hline & & & t-ratio & 1.52 & 8.79 & -0.69 & 2.71 & 8.08 & 0.07 & 2.04 & 7.17 \\
\hline \multirow{3}{*}{ High } & \multirow{3}{*}{ Old } & \multirow{3}{*}{ Northeast } & Mean & 0.031 & 5.389 & -0.013 & 0.032 & 3.066 & -0.004 & $0.75 \%$ & $4.42 \%$ \\
\hline & & & Std dev & 0.012 & 0.317 & 0.004 & 0.009 & 0.242 & 0.004 & $0.10 \%$ & $0.32 \%$ \\
\hline & & & t-ratio & 2.50 & 17.00 & -2.93 & 3.46 & 12.70 & -1.26 & 7.46 & 13.79 \\
\hline \multirow{3}{*}{ Low } & \multirow{3}{*}{ Young } & \multirow{3}{*}{ South/Southeast } & Mean & 0.121 & 4.940 & -0.011 & 0.063 & 1.787 & -0.004 & $0.74 \%$ & $12.79 \%$ \\
\hline & & & Std dev & 0.058 & 0.496 & 0.008 & 0.018 & 0.180 & 0.003 & $0.15 \%$ & $0.89 \%$ \\
\hline & & & t-ratio & 2.08 & 9.95 & -1.28 & 3.42 & 9.90 & -1.43 & 4.93 & 14.33 \\
\hline \multirow{3}{*}{ Medium } & \multirow{3}{*}{ Young } & \multirow{3}{*}{ South/Southeast } & Mean & 0.043 & 4.823 & -0.016 & 0.070 & 1.865 & -0.006 & $1.51 \%$ & $13.01 \%$ \\
\hline & & & Std dev & 0.022 & 0.292 & 0.004 & 0.015 & 0.151 & 0.003 & $0.22 \%$ & $0.91 \%$ \\
\hline & & & t-ratio & 1.91 & 16.51 & -3.74 & 4.57 & 12.37 & -2.43 & 6.88 & 14.37 \\
\hline \multirow{3}{*}{ High } & & & Mean & 0.074 & 4.023 & -0.013 & 0.066 & 1.636 & -0.005 & $2.55 \%$ & $14.96 \%$ \\
\hline & Young & South/Southeast & Std dev & 0.013 & 0.206 & 0.004 & 0.011 & 0.170 & 0.003 & $0.13 \%$ & $0.63 \%$ \\
\hline & & & t-ratio & 5.51 & 19.49 & -3.75 & 6.02 & 9.60 & -1.78 & 19.34 & 23.66 \\
\hline & & & Mean & 0.059 & 5.088 & -0.016 & 0.049 & 1.730 & -0.006 & $1.01 \%$ & $14.67 \%$ \\
\hline Low & Old & South/Southeast & Std dev & 0.013 & 0.242 & 0.004 & 0.007 & 0.096 & 0.002 & $0.09 \%$ & $0.52 \%$ \\
\hline & & & t-ratio & 4.37 & 21.06 & -4.13 & 7.18 & 17.99 & -3.58 & 11.14 & 28.13 \\
\hline & & & Mean & 0.035 & 4.882 & -0.016 & 0.068 & 1.922 & -0.005 & $1.48 \%$ & $11.11 \%$ \\
\hline Medium & Old & South/Southeast & Std dev & 0.015 & 0.402 & 0.007 & 0.015 & 0.228 & 0.004 & $0.27 \%$ & $1.34 \%$ \\
\hline & & & t-ratio & 2.26 & 12.14 & -2.49 & 4.48 & 8.45 & -1.24 & 5.48 & 8.31 \\
\hline & & & Mean & 0.044 & 4.321 & -0.014 & 0.061 & 2.223 & -0.006 & $2.33 \%$ & $9.53 \%$ \\
\hline High & Old & South/Southeast & Std dev & 0.011 & 0.234 & 0.004 & 0.009 & 0.167 & 0.002 & $0.16 \%$ & $0.49 \%$ \\
\hline & & & t-ratio & 4.05 & 18.43 & -3.90 & 7.14 & 13.33 & -2.56 & 14.26 & 19.48 \\
\hline
\end{tabular}

Note: Means and standard deviations were calculated using bootstrap resampling techniques

Source: Authors' calculation using PME (IBGE) 
The results also show that formal jobs offers have been increasing over time. Indeed, the parameters capturing the time trend are practically all negative and significant for formal offers. For the informal offers, although some of the estimates are not significant, the pattern is the same. Conversely, the duration of the unemployment spell is inversely related to the offer probabilities for both the eligible and the non-eligible individuals. For the eligible, this finding differs from what some of the empirical evidences suggest, since in some countries the search effort (and thus offer rates) increases when benefits exhaustion is approaching. The implication in the case of Brazil is that workers, even if they receive unemployment benefits, would like to get a job and are not waiting until the last minute to find one.

Table 7a-Parameters estimates for eligible men

\begin{tabular}{clrrrrrr|rr}
\hline Education & & $\boldsymbol{\theta}_{\mathbf{F}}$ & $\boldsymbol{\beta}_{\mathbf{F}}$ & $\boldsymbol{\tau}_{\mathbf{F}}$ & $\boldsymbol{\theta}_{\mathbf{I}}$ & $\boldsymbol{\beta}_{\mathbf{I}}$ & $\boldsymbol{\tau}_{\mathbf{I}}$ & $\boldsymbol{v F}$ & $\boldsymbol{v} \mathbf{c}$ \\
\hline \multirow{4}{*}{ Low } & Mean & 0.171 & 4.136 & -0.022 & 0.284 & 0.930 & -0.003 & $3.72 \%$ & $22.49 \%$ \\
& Std dev & 0.112 & 0.340 & 0.005 & 0.089 & 0.232 & 0.004 & $0.47 \%$ & $1.93 \%$ \\
& t-ratio & 1.52 & 12.16 & -4.62 & 3.19 & 4.00 & -0.81 & 7.85 & 11.66 \\
\hline \multirow{4}{*}{ Medium } & Mean & 0.097 & 3.235 & -0.008 & 0.136 & 0.882 & -0.003 & $4.83 \%$ & $27.14 \%$ \\
& Std dev & 0.084 & 0.284 & 0.004 & 0.098 & 0.293 & 0.004 & $0.55 \%$ & $2.29 \%$ \\
& t-ratio & 1.15 & 11.38 & -1.77 & 1.39 & 3.01 & -0.59 & 8.71 & 11.87 \\
\hline \multirow{3}{*}{ High } & Mean & -0.011 & 4.009 & -0.013 & 0.019 & 1.493 & -0.003 & $3.91 \%$ & $20.69 \%$ \\
& Std dev & 0.069 & 0.360 & 0.004 & 0.055 & 0.234 & 0.003 & $0.64 \%$ & $1.41 \%$ \\
& t-ratio & -0.17 & 11.14 & -2.92 & 0.34 & 6.38 & -0.99 & 6.08 & 14.73 \\
\hline
\end{tabular}

Note: Means and standard deviations were calculated using bootstrap resampling techniques Source: Authors' calculation using PME (IBGE)

Table $7 b$ - Parameters estimates for eligible women

\begin{tabular}{|c|c|c|c|c|c|c|c|c|c|}
\hline Education & & $\theta_{F}$ & $\beta_{F}$ & $\tau_{F}$ & $\theta_{\text {I }}$ & $\beta_{I}$ & $\tau_{I}$ & $\mathbf{v F}$ & vI \\
\hline \multirow{3}{*}{ Low } & Mean & 0.406 & 3.970 & -0.008 & 0.294 & 1.407 & -0.020 & $1.99 \%$ & $29.48 \%$ \\
\hline & Std dev & 0.339 & 0.978 & 0.014 & 0.253 & 0.569 & 0.010 & $0.69 \%$ & $4.21 \%$ \\
\hline & t-ratio & 1.20 & 4.06 & -0.57 & 1.16 & 2.47 & -1.97 & 2.88 & 7.00 \\
\hline \multirow{3}{*}{ Medium } & Mean & 0.374 & 3.386 & -0.004 & 0.099 & 1.064 & -0.002 & $2.89 \%$ & $25.22 \%$ \\
\hline & Std dev & 1.218 & 0.638 & 0.010 & 0.132 & 0.507 & 0.008 & $0.66 \%$ & $3.96 \%$ \\
\hline & t-ratio & 0.31 & 5.30 & 0.47 & 0.75 & 2.10 & -0.28 & 4.36 & 6.36 \\
\hline \multirow{3}{*}{ High } & Mean & 0.028 & 4.382 & -0.020 & 0.193 & 1.726 & -0.004 & $3.89 \%$ & $13.87 \%$ \\
\hline & Std dev & 0.067 & 0.343 & 0.005 & 0.067 & 0.218 & 0.003 & $0.45 \%$ & $1.11 \%$ \\
\hline & t-ratio & 0.42 & 12.79 & -4.22 & 2.88 & 7.90 & -1.24 & 8.70 & 12.50 \\
\hline
\end{tabular}

Note: Means and standard deviations were calculated using bootstrap resampling techniques Source: Authors' calculation using PME (IBGE)

\section{Policy Simulations}

We start by illustrating how the model can be used to analyze the effect of changes in unemployment benefits. Figure 1 graphs the value of an informal job offer (left panel) and a formal job offer (right panel) as 
a function of the value of waiting. The figure refers to male, low-skilled workers who are older than 24 years, leave in the South or Southeast region and are not eligible for unemployment benefits. In the figure, the offered wage considered when calculating the expected value of waiting is set at the average of each individual distribution, whereas a zero-mean shock is added to the expected wage used for the calculation of the formal and informal offers in order to mimic the observed wage distribution. ${ }^{13}$ We see that in the case of informal job offers, approximately half of the points lie above the $45^{\circ}$ line, meaning that a large portion of informal offers are refused. In such cases, individuals choose to wait for a higher wage or a formal sector job. For formal job offers, on the other hand, the majority of points are above the $45^{\circ}$ line indicating that most individuals would accept a formal job offer (that pays the expected wage) instead of remaining unemployed.

In Figure 2 we reproduce the two panels but this time after giving unemployment assistance to all workers. The value of the transfer is set to $40 \%$ of the mean of the worker's wage distribution, and the benefit is paid as long as she is unemployed. We see that for both informal and formal job offers, a great share of the points move below the $45^{\circ}$ line. Thus, a sizeable unemployment assistance transfer can have a sizeable effect on exit probabilities from unemployment and, as predicted by theory, increase the unemployment rate.

Figure 1 - Value function in baseline scenario (Men, non eligible, low education, 24 years old or more and south/southeast region)
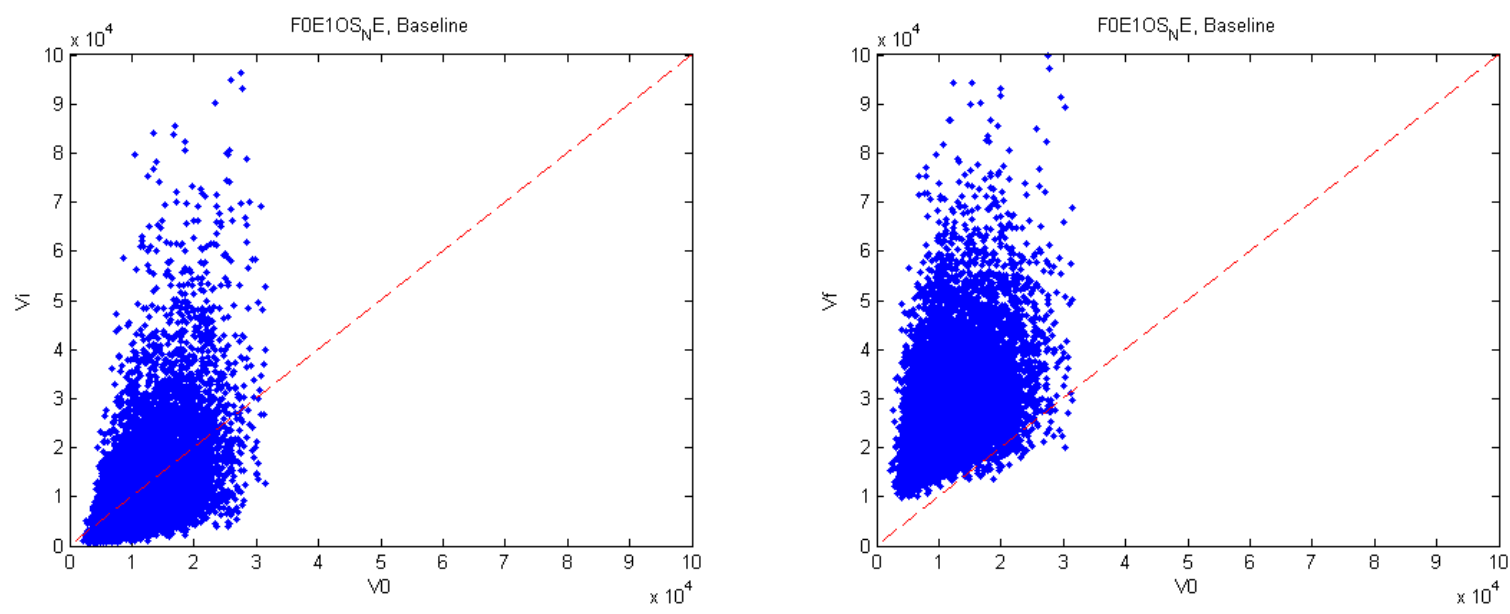

\footnotetext{
${ }^{13}$ The variance of the shock is calculated based on the difference of the observed variance and the variance obtained by the wage estimation equations (taking into account Heckman's correction procedure)
} 
Figure 2 - Value function with Unemployment Assistance (Men, non eligible, low education, 24 years old or more and south/southeast region)
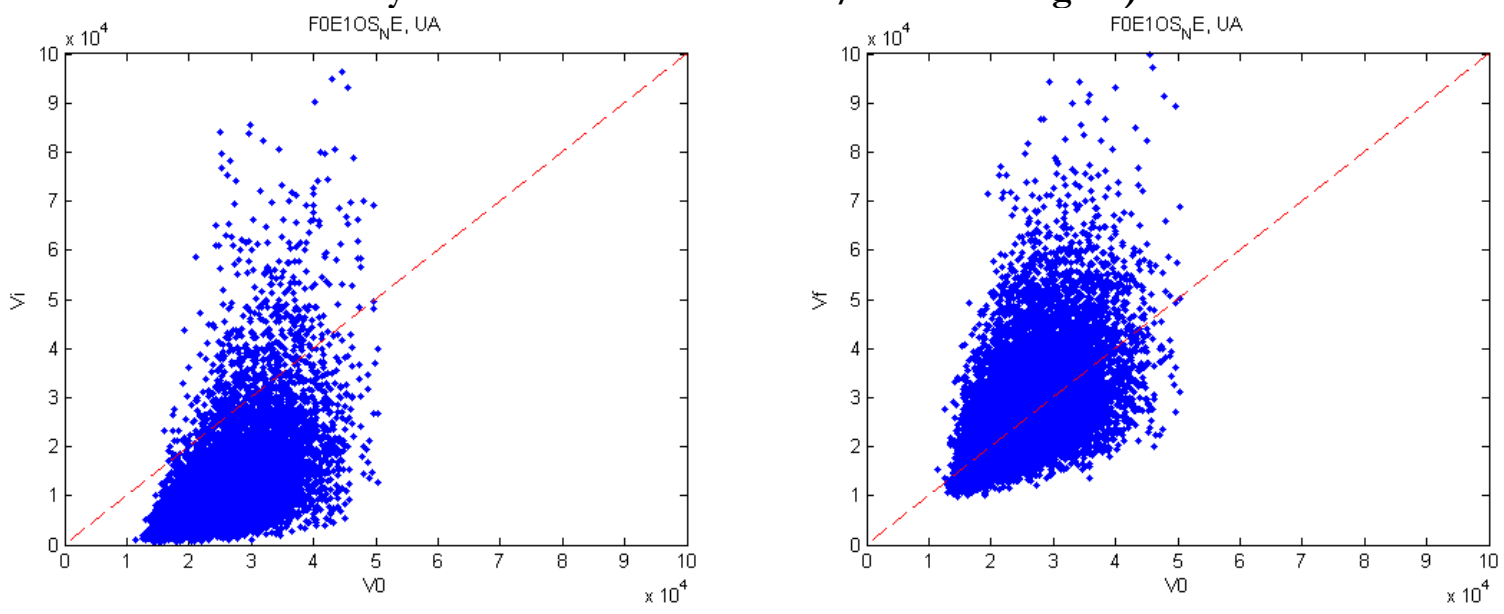

We are interested in understanding the effect that the current unemployment insurance component and the savings component of the Brazilian UB system have on exit probabilities from unemployment into formal and informal sector jobs, and how these probabilities change when benefits or contributions increase. To this end, we conduct six types of simulations that we apply to all groups described in the previous section: (i) eliminating unemployment benefits; (ii) eliminating FGTS; (iii) eliminating both UI and FGTS; (iv) providing an additional benefit of $40 \%$ of the mean of the worker's wage distribution that is paid for as long as they are unemployed; (v) increasing the contribution rate to finance unemployment benefits from currently zero $^{14}$ to $5 \%$; and (vi) increasing the contribution rate to $10 \% .{ }^{15}$ The results are summarized in Figure 3, 4, 5 and 6, respectively for eligible and non-eligible males and eligible and non-eligible women. In each panel, there are three bars for each policy (6 triplets of bars) that give the percentage change in the transition probabilities. Basically, changes in the percentage of workers moving into formal jobs, informal jobs, or remaining unemployed. For non eligible males and females the policy changes only affect the value of future job offers, while for eligible males and females the changes affect both current benefits and the future value of the job offers.

The results first show that the impact of the current unemployment insurance system (risk-pooling) on transitions rates out of unemployment is generally small, particularly for skilled workers. Among eligible individuals (males and females) removing the unemployment insurance component of the UB system would mainly increase transition probabilities into informal jobs (between 15 and 18 percent) and induce only a small reduction in the share of workers who remain unemployed. To interpret these results it is important to remember that removing unemployment insurance has two effects on transitions to formal sector jobs. First, because there is no more unemployment compensation, the reservation wage falls and thus transitions to formal jobs should rise. On the other hand, the value of formal offers is reduced because of the absence of

\footnotetext{
${ }^{14}$ Recall that the unemployment insurance component is financed from revenue taxes on employers.

${ }^{15}$ Today employers contribute $8 \%$ of workers salary to the savings accounts. We assume that workers would be responsible for this contribution plus an additional 2 percentage points to finance unemployment benefits.
} 
future benefits, making formal jobs less attractive and thus leading to a reduction in the value of waiting and an increase the relative value of informal job offers. Our results show that only in the case of high skilled females the first effect dominates and thus transitions to formal jobs increase, albeit only slightly. In all other cases, the transitions to formal jobs are reduced (by less than one percent). The results are more pronounced for females than males and for low skilled individuals.

For those who are not eligible the effects are similar. The main difference is that the probabilities of transition to formal jobs always declines, because this time the only effect is that formal jobs become less attractive and workers are less inclined to wait for them. As a result, transition probabilities into informal sector jobs increase and contribute to reduce the percentage of workers who remain unemployed.

It is very important to note that, as we had discussed in the introduction, these effects of the unemployment insurance system are conditional on its current design. To show this, we simulated the impact of giving unemployment benefits with replacement rates of 40 percent. Clearly, in that case, there would be major reductions in the transition probabilities to both formal and informal sector jobs, and an increase in the share of workers who remain unemployed - particularly among low income workers.

The effects of removing FGTS are similar for both eligible and non-eligible individuals. Because formal sector jobs become less attractive (unemployment savings are also funded exclusively by the employer ${ }^{16}$ ) workers have, again, fewer incentives to wait for them and are more likely to take informal sector jobs. This reduces slightly the unemployment rate. In addition, eliminating entirely the UB system "ads" the negative effects that both unemployment insurance and FGTS have on the share of worker who remain unemployed. The largest "joint effect" that we find is for eligible women with medium education, for whom the share of those unemployed could be reduced by 3 percent and the transitions to informal jobs would increase by 21 percent.

We finally look at the effects of asking workers to contribute to finance UI and FGTS - in both cases by reducing their wages. As before, the results are similar for eligible and non-eligible workers. The main effect of the pay-roll tax is to reduce the value of formal jobs and provide incentives to take informal sector jobs. Again, this also reduces slightly the length of the unemployment spell as individuals have fewer incentives to wait for formal sector jobs.

\footnotetext{
${ }^{16}$ In this case eliminating FGTS could increase wages but the assumption here is that wages remain unchanged.
} 
Figure 3 - Change (\%) on transition probabilities (men, eligible)
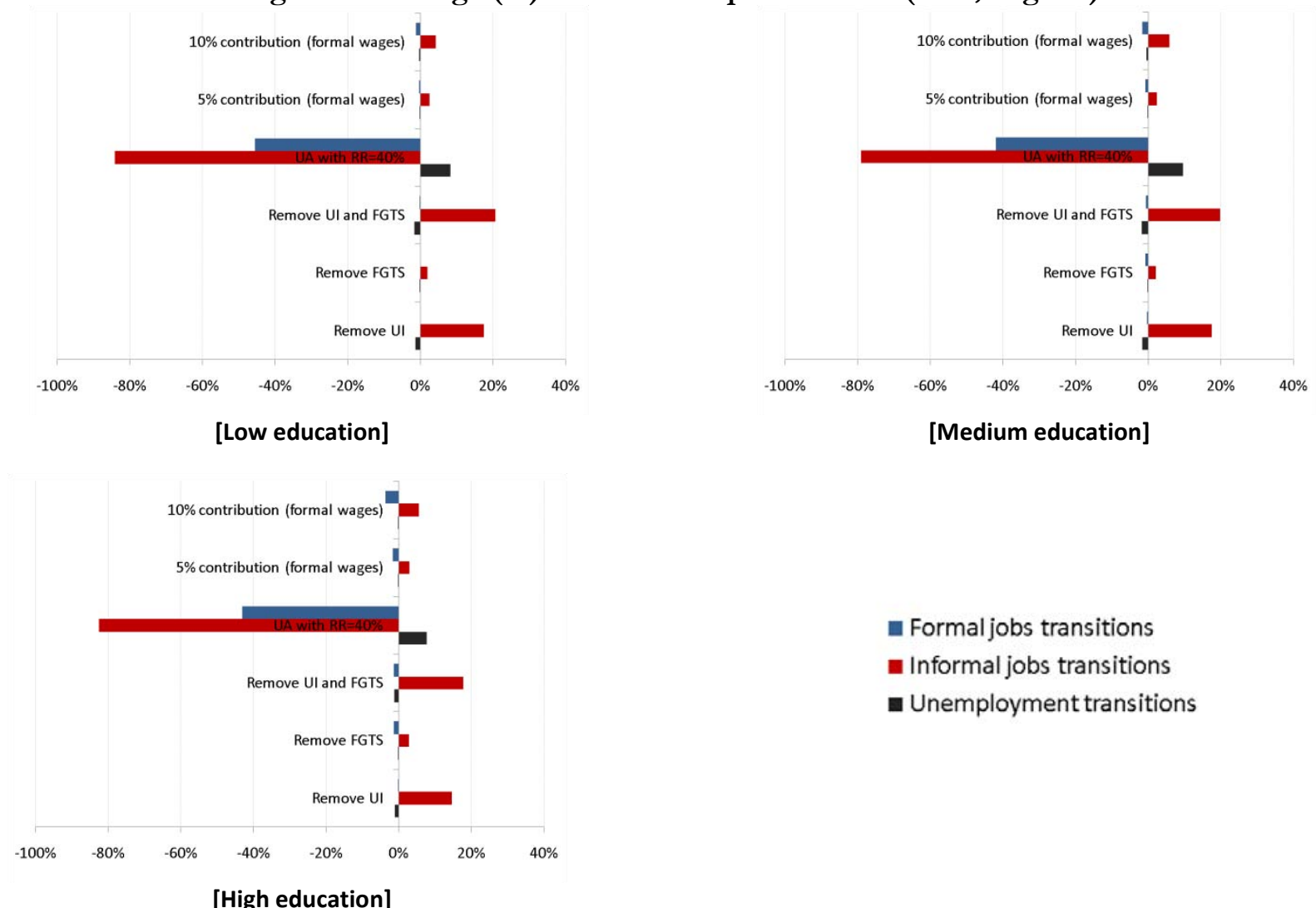

Figure 4 - Change (\%) on transition probabilities (women, eligible)
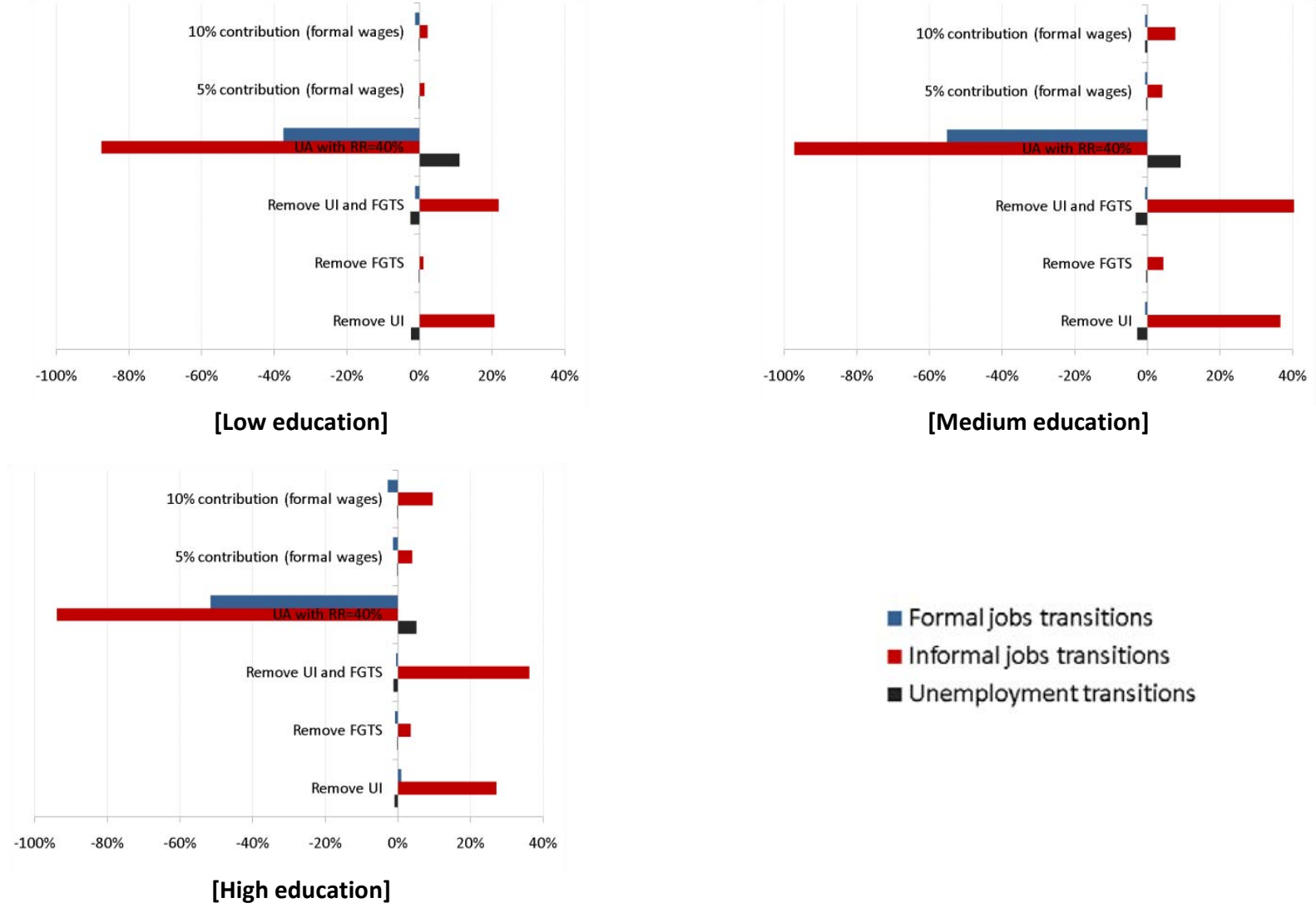

- Formal jobs transitions

- Informal jobs transitions

- Unemployment transitions

[High education] 
Figure 5 - Change (\%) on transition probabilities (men, non eligible)
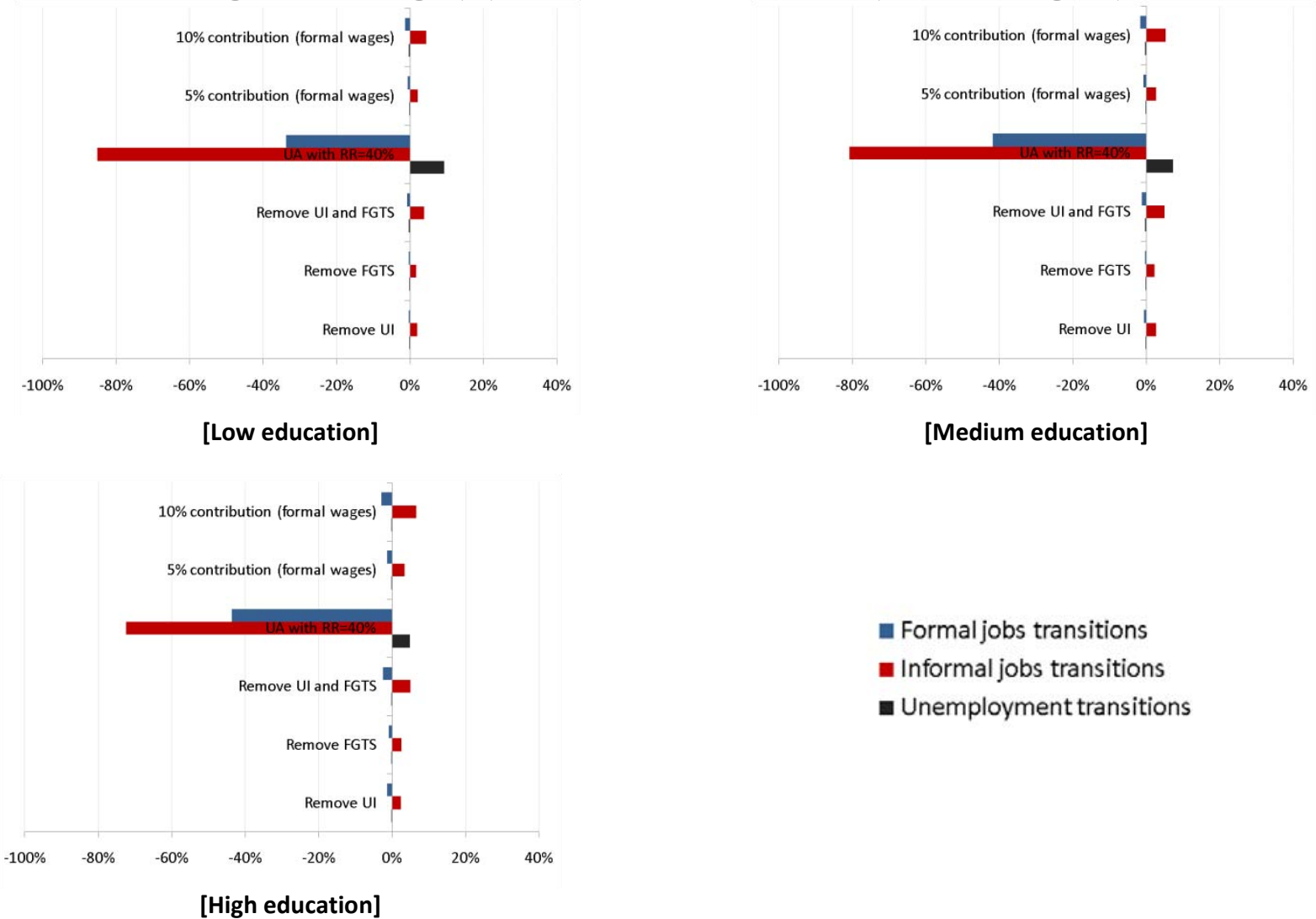

- Formal jobs transitions

- Informal jobs transitions

- Unemployment transitions

Figure 6 - Change (\%) on transition probabilities (women, non eligible)
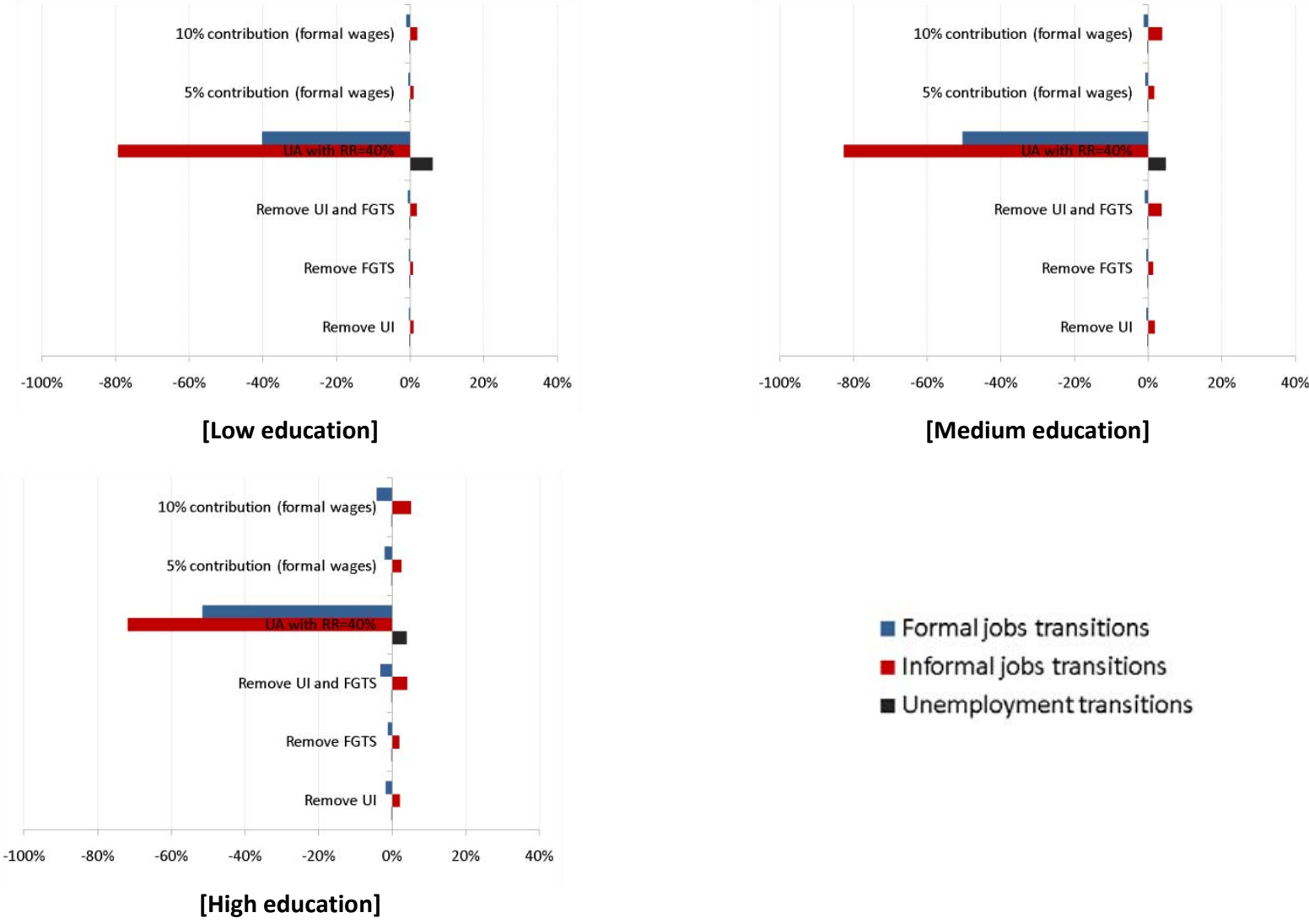

- Unemployment transitions 


\section{Conclusions}

In this paper we have developed a simply behavioral model where workers receive formal and informal job offers and decide whether to take them or wait. We use the model to assess the impact of the Brazilian unemployment benefit (UB) system on transition rates out of unemployment into formal and informal sector jobs. After incorporating, in detail, the rules of the UB system, the parameters of the model were we estimated using a panel dataset of unemployed workers. We produced separate estimates for 30 groups of workers based on gender, education (low, medium, and high), region (Northeast and South/Southeast), age (younger and older than 24 years) and eligibility for unemployment benefits. Most of the parameters estimates for non-eligible workers are statistically significant and lead to monthly offer probabilities ranging between $0.1 \%$ and $3.8 \%$ for formal jobs, and $4.4 \%$ and $25.6 \%$ for informal jobs. For eligible individuals, because of the small size of the sub-samples, some estimates were not significant. Overall, however, we find offer probabilities ranging between $2.0 \%$ and $4.8 \%$ for formal jobs and between $13.9 \%$ to $29.5 \%$ for informal jobs. We also report that there seems to be a clear positive trend in the probabilities of offer arrivals, indicating a non-stationary condition.

We conducted six types of policy simulations: (i) eliminating unemployment benefits; (ii) eliminating FGTS; (iii) eliminating both UI and FGTS; (iv) providing a benefit of $40 \%$ of the mean of worker's wage distribution that lasts for the entire unemployment spell; (v) increasing the contribution rate to finance unemployment benefits from currently zero ${ }^{17}$ to $5 \%$; and (vi) increasing the contribution rate to $10 \%$. The results suggest that the effects of the current unemployment insurance (UI) system and the unemployment savings account (FGTS) on exit rates from unemployment are small. The largest effects are observed among low and medium skilled workers, particularly women, but they remain modest. The main effect of the two systems is to reduce transitions into informal sector jobs. This happens because both UI and FGTS, which are financed by the employer, increase the value of formal sector jobs, thus providing incentives for workers to wait for these jobs - instead of taking informal jobs. Thus, indirectly, UI and FGTS also affect unemployed workers who are not eligible for benefits.

The results also show that, ultimately, the effect of the unemployment benefit system on workers behaviors depends on its design. For instance, increasing the replacement rate and the duration of benefits of the UI system can reduce considerably transitions out of unemployment. Similarly if, in the case of Brazil, workers had to contribute to finance unemployment insurance and unemployment savings, there would be less formal work.

A general implication for policy is that, with a careful design, unemployment benefit systems can be used in middle income countries to provide better protection to workers, without having a major effect on the length of unemployment spells. Savings arrangements, in particular, would not create moral hazard while providing incentives to individuals to take formal sector jobs (as long as mandatory savings are not too high).

\footnotetext{
${ }^{17}$ Recall that the unemployment insurance component is financed from revenue taxes on employers.
} 
Unemployment insurance can also be an alternative but attention needs to be given to the level of the benefits. Benefits that are too high can have a negative impact on employment.

\section{References}

Barros, R. de, C. Corseuil and M. Bahia. 1999. "Labor Market Regulations and the Duration of Employment in Brazil.” IPEA Working Paper No. 676. Rio de Janeiro: Institute of Applied Economic Research.

Bosch, M. and W. Maloney. 2007. "Comparative Analysis of Labor Market Dynamics Using Markov Processes: An Application to Informality.” IZA Discussion Paper Series No. 3038. Bonn: Institute for the Study of Labor / World Bank Policy Research Working Paper No. 4429. Washington DC: World Bank.

Corseuil, C. H.; Ribeiro, E. P.; Santos, D. (2003). Job and Worker Flows in Brazil, Mimeo 2003.

Cunningham, W. 2000. "Unemployment Insurance in Brazil: Unemployment Duration, Wages and Sectoral Choice," Technical Report. Washington DC: World Bank.

Diamond, P. 1982. "Wage determination and efficiency in search equilibrium". Review of Economic Studies 49 (2), 217-227.

Gonzaga, G. 2003. "Labor Turnover and Labor Legislation in Brazil," Economía: Journal of the Latin America and Caribbean Association 4(1): 165-221.

Holmlund, B. 1998. 'Unemployment Insurance in Theory and Practice', Scandinavian Journal of Economics, Vol. 100, No. 1, pages 113-141

Kugler, A.D. 1999. "The Impact of Firing Costs on Turnover and Unemployment: Evidence from the Colombian Labour Market Reform," Economics Working Papers 388, Department of Economics and Business, Universitat Pompeu Fabra.

Margolis, D. (2008). "The Effect of Unemployment Insurance on Formal and Informal Sector Employment in Brazil." Washington DC: World Bank, mimeo.

Mello, R. F; Santos, D. (2009), “Aceleração Educacional e a Queda Recente da Informalidade”, Boletim de Mercado de Trabalho, No.39, IPEA.

Montenegro, C.; Pages, C. 2003. "Who Benefits from Labor Market Regulations? Chile 1960-1998”, NBER Working Papers 9850, National Bureau of Economic Research, Inc.

Mortensen, D. T. (1986). "Job search and labor market analysis" Chapter 15, Handbook of Labor Economics, Vol. 2, O. Ashenfelter and R. Layard, eds., North-Holland

Pagés, C., and C.E. Montenegro. 1999. "Job Security and the Age Composition of Employment: Evidence from Chile.” Research Department Working Paper 398. Washington, DC, United States: Inter-American Development Bank.

Pissarides, C. 1990. "Unemployment And The Persistence On Employment Shocks". Papers 377, London School of Economics - Centre for Labour Economics. 
Robalino, David A.; Zylberstajn, Eduardo; Zylberstajn, Helio; Afonso, Luis Eduardo, 2009. "Ex-ante methods to assess the impact of social insurance policies on labor supply with an application to Brazil," Policy Research Working Paper Series 5027, The World Bank

Saavedra, J.; Torero, M. 2004. "Labor Market Reforms and their Impact over Formal Labor Demand and Job Market Turnover: The Case of Peru." In Law and Employment: Lessons from Latin America and the Caribbean,.ed. J. Heckman and C. Pagés. Chicago: University of Chicago and National Bureau of Economic Research.

Van den Berg, G.J. 1990. "Nonstationarity in job search theory”. Review of Economic Studies 57, 255-277.

Wolpin, K. I. 1987. "Estimating a Structural Search Model: The Transition from School to Work". Econometrica, Vol. 55, No. 4 (Jul., 1987), pp. 801-817 


\section{Annex: The Brazilian unemployment benefits' system}

\section{The Brazilian Labor Market}

The Brazilian labor market can be characterized by a large informal sector and a high labor turnover (World Bank, 2002). However, it is important to state that the informal sector has been in a persistent and important decline, perhaps due to the increase in the education level of the work force (Melo and Santos, 2009). Still, informality comprises roughly $50 \%$ of the labor force, according to IBGE (Instituto Brasileiro de Geografia e Estatística, or Brazilian National Statistical Agency). Informal workers, which includes basically self-employed and workers sem carteira (without contract), do not have any access to income protection systems. In accordance to the literature, formal workers in Brazil were considered those who had a signed labor card (signed carteira).

Corseuil et al. (2003) find that the yearly job reallocation averaged 33\% between 1991 and 1998, whereas Bosch and Maloney (2007) show that the average job tenure, around 4.5 years with the same employer for formal sector jobs, is one of the lowest in the world. They also show that the duration of selfemployment and informal sectors jobs is respectively 2.3 years and a little less than one year.

According to Margolis (2008), there are two contradictories welfare effects of this high labor turnover. First, a flexible labor market can facilitate job reallocations and therefore be growth enhancing, since low productivity jobs are not perpetuated. On the other hand, the high degree of income uncertainty might have a direct effect on the well-being of individuals and in the economic efficiency, as it could encourage the unemployed to accept any offer they receive (thereby crowding out potentially more productive matches). Another harmful effect of high labor turnover is the disincentive it brings to investments in human capital, again reducing the economic efficiency.

\section{Income Protection in Brazil}

Brazil has two different income protection systems: A traditional risk pooling unemployment insurance (UI) and an unemployment individual savings account (UISA), named FGTS. According to current legislation, formal sector workers who lose their jobs after a certain number of months of contributions become eligible for unemployment insurance benefits and acquire the right to cash all the balance from their FGTS accounts. To be eligible for and trigger the start of UI, besides being fired, workers need to have held a formal sector job for at least 6 months in the previous 36-month period.

The duration of the benefit ranges between 3 and 5 months depending on the contribution period. If contributions ranged between 6 to 11 months, workers receive 3 months of benefits; with 12 to 23 they get 4 months and, finally, with 24 to 36 they receive 5 months. The benefit itself depends on average earnings 
during the contribution period: in 2010 the benefit ranged between $\mathrm{R} \$ 510$ (the legally minimum wage, around US\$280) and R \$ 954.21 (around USD 530). For those whose average monthly salary is less than R\$ 841.89, the benefit formula is simply the minimum between $\mathrm{R} \$ 510$ and $80 \%$ of the average earnings. Above this intermediate boundary, benefits are smaller and limited by the top boundary. The benefit formula ensures that replacement rates are higher for low than for high income workers (see top-left panel of Figure 1). Normally, benefits are readjusted once a year, at the same time as the minimum wage.

Besides UI, each formal worker in Brazil has an UISA. Employers are obliged to deposit the equivalent to $8 \%$ of the monthly wage every month into these accounts, which are administrated by CAIXA, a federal bank. When fired without cause, workers are allowed to cash the balance accumulated in their FGTS accounts while working in their last job plus a dismissal fine equal to 40 percent of the accumulated assets. This is a lump sum payment. Other than dismissal without cause, workers have access to their balances in only a few scenarios (severe disease, retirement, death and housing, for instance).

According to Robalino et al. (2009), the replacement rates offered by the UI system range between 40 and 100 percent depending on the level of income. Taking both UI and FGTS together, the median worker can finance between 3.5 and 8 months of salaries depending on the number of months of contributions (see top-right panel of Figure 1) if fired without cause. Nonetheless, redistribution within the system seems to be regressive because low income workers have lower take-up rates and lower average benefits (see bottom panel of Figure 1).

With respect to FGTS, there are basically two concerns. First, that it might provide incentives for fake dismissals in order to workers cash-out their savings. Robalino et al. (2009) argue that this could happen if the rates of return on FGTS savings were consistently below market (which indeed has been the case in recent years), if the mandate for precautionary savings is too high and/or credit constraints impede dissavings. Second, employers may prefer short-term contracts to avoid paying higher dismissal fines (Barros et al. 1999; Gonzaga, 2003). 
Figure A1: Mandate of the Income Protection System and Redistribution
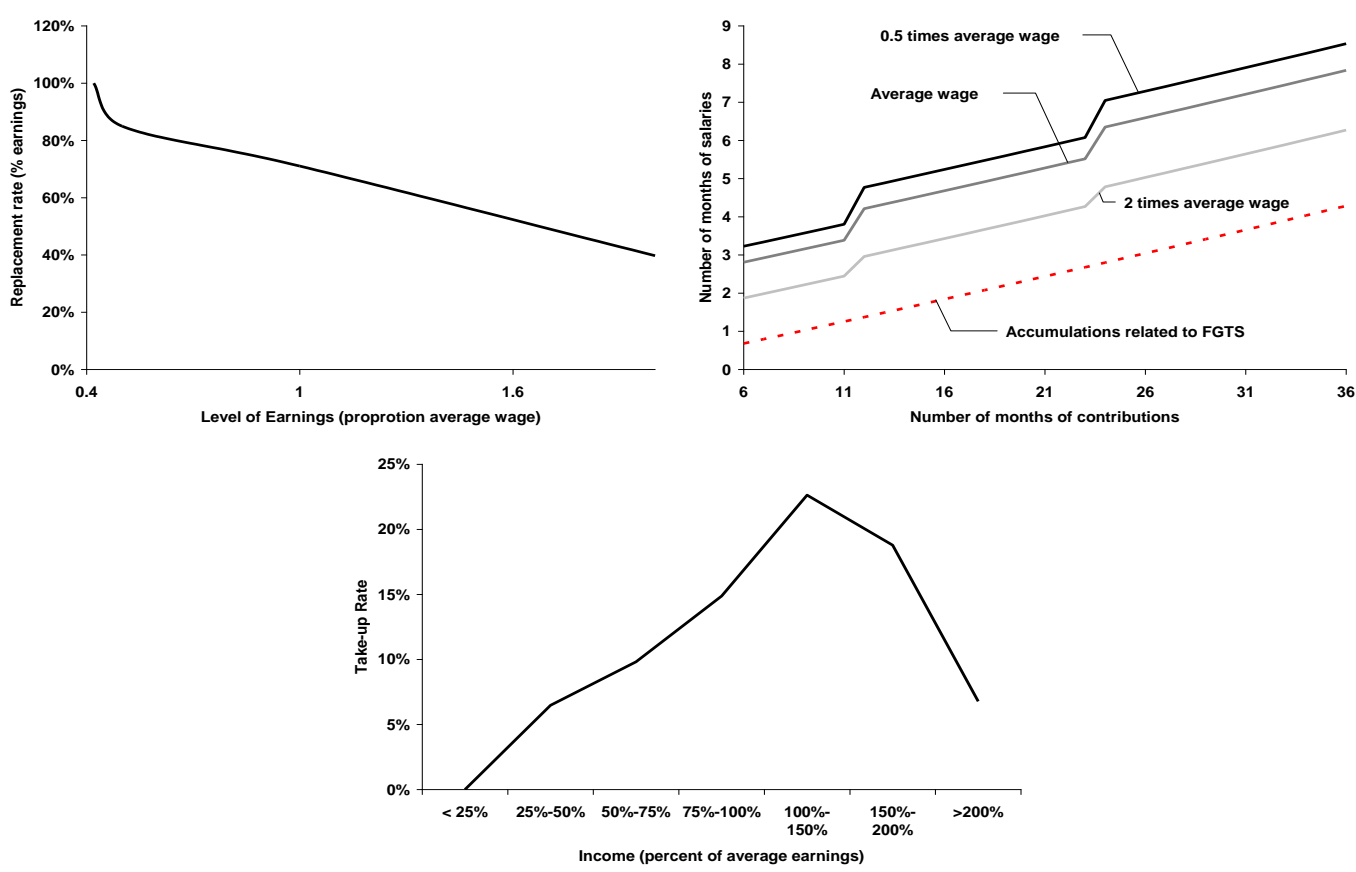

Source: Robalino et al. (2009).

\section{Annex 2: Testing the Validity of the Estimation Procedure}

The purpose of this section is to validate the methodology used to estimate the model parameters. We do this by using simulated data (i.e., data generated with a known set of model parameters). We can then compare whether the estimates are equal to the true parameter values.

We start by running a simulation with 1,000 individuals characterized by their formal and informal wage distributions, which are log-normally distributed. The means and variances that define these wage distributions are sampled from exogenously defined normal distributions (one distribution for the means and one for the variances). Individuals are followed over time, month by month, for a period of 40 years. Like in the model described in the main text, when unemployed they are offered a formal or informal job with probabilities $v_{F}$ and $v_{I}$ respectively, which depend on the parameters $\theta_{F}, \beta_{F}, \theta_{I}, \beta_{I}$ as indicated in the main text (we excluded the time trend). If offered a job, the corresponding salary is sampled from their respective wage distributions. Individual then decide to accept the offer based on the monetary values of the options. When employed, they can lose their job with a 0.025 probability if in the formal sector and with a 0.05 probability if in the informal sector. 
We store the "work histories" of all individuals, creating a database with a similar structure than the real data used in this paper. The idea then is to apply the maximum likely-hood estimation described in the main text to recover the parameters $\theta_{F}, \beta_{F}, \theta_{I}, \beta_{I}$.

In the exercise, the parameters were calibrated so that the probability of an informal job offer was 0.2 in the first month of unemployment and 0.1 in the $6^{\text {th }}$ month. Similarly, the probability of a formal job offer was 0.1 in the first month and 0.05 in the $6^{\text {th }}$ (See Figure A1). The coefficients respecting these constraints are:

$\beta_{F}=2.0478 ; \theta_{F}=0.1494 ; \beta_{I}=1.2241 ; \theta_{I}=0.1622$.

We define the likelihood function as described in section 4 of the main text. Figure A2 graphs this likelihood function with respect to $\beta_{F}$ and $\theta_{F}$ (holding $\beta_{I}$ and $\theta_{I}$ constant). We notice that the function is smooth and has indeed a well-defined maximum. The results of the optimization came up to be: $\beta_{F}=2.055 ; \theta_{F}=$ $0.1457 ; \beta_{I}=1.2362 ; \theta_{I}=0.1583$ - very close to the original values.

Figure A1: Probability of a job offer by months of unemployment

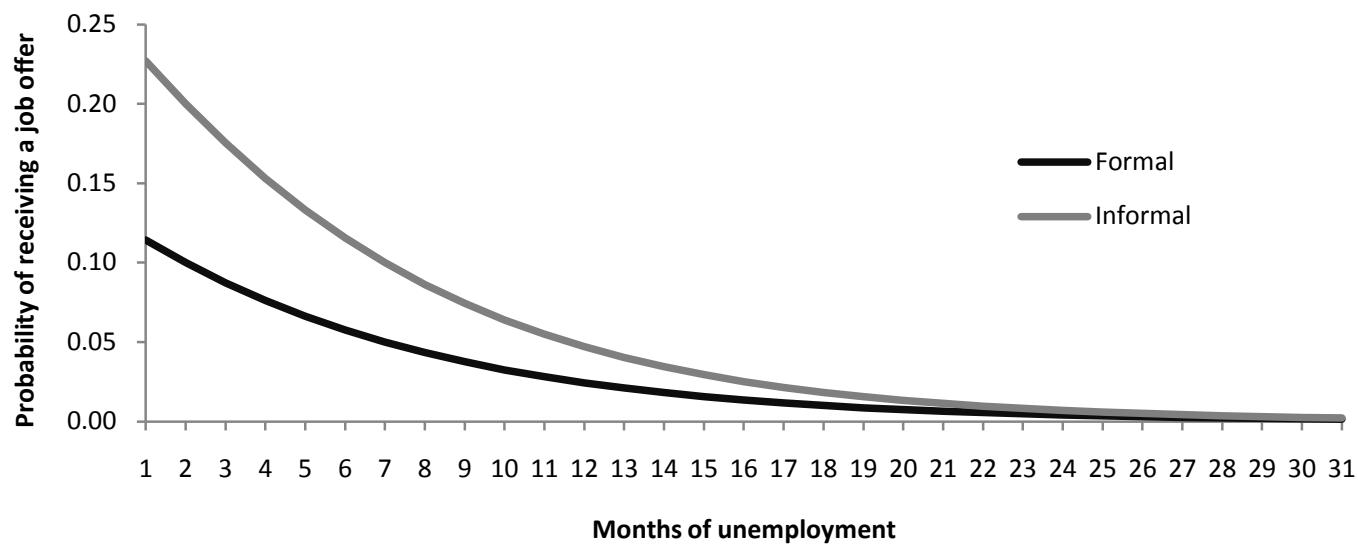


Figure A2: Likelihood function with respect to $\beta_{F}$ and $\theta_{F}$

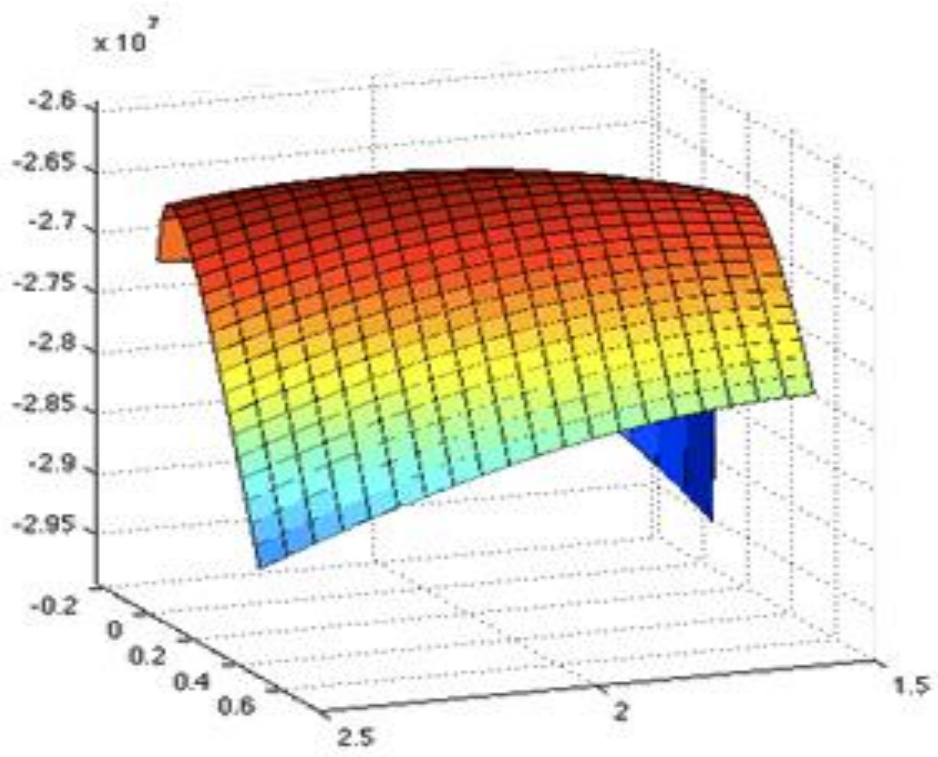

